\title{
Comparison of the gasification performance of multiple biomass types in a bubbling fluidized bed
}

M. P. González-Vázquez, R. García, M. V. Gil*, C. Pevida, F. Rubiera

Instituto Nacional del Carbón, INCAR-CSIC, Francisco Pintado Fe 26, 33011 Oviedo, Spain

\begin{abstract}
The present study investigates the air-steam gasification of ten commercial and alternative lignocellulosic biomass fuels (pine sawdust, chestnut sawdust, torrefied pine sawdust, torrefied chestnut sawdust, almond shells, cocoa shells, grape pomace, olive stones, pine kernel shells and pine cone leafs) in order to evaluate the product gas composition and the process performance in a bubbling fluidized bed gasifier with focus on the different biomass properties. Accordingly, an effort to correlate the biomass characteristics with the gasification results has been done. Pine kernel shell (PKS) was used to test the effect of the gasification temperature $\left(700,800\right.$ and $\left.900{ }^{\circ} \mathrm{C}\right)$, steam to air ratio in the gasifying agent $(\mathrm{S} / \mathrm{A}=10 / 90,25 / 75,50 / 50$ and 70/30) and stoichiometric ratio $(\mathrm{SR}=0.13$ and 0.25$)$ on the product gas composition, combustible gas $\left(\mathrm{H}_{2}+\mathrm{CO}+\mathrm{CH}_{4}\right)$ production, $\mathrm{H}_{2} / \mathrm{CO}$ ratio, heating value, energy yield and cold gas efficiency of the obtained gas. Results showed that higher temperature and S/A ratio favored $\mathrm{H}_{2}$ production and gasification performance. A higher value of SR slightly affected the gas composition, but led to a higher process efficiency as a consequence of a higher biomass conversion into gaseous combustible products. All the biomass samples of different origin and characteristics were then gasified at the best experimental conditions found $\left(900{ }^{\circ} \mathrm{C}\right.$, $\mathrm{S} / \mathrm{A}=70 / 30, \mathrm{SR}=0.25)$. Gasification of all the biomasses was feasible and $\mathrm{H}_{2}$ and combustible gas concentrations of 30-39 vol\% and 59-78 vol\% (inert gas-free basis), respectively, were obtained for the biomasses studied, with energy yields of 8-18 $\mathrm{MJ} / \mathrm{kg}_{\text {biomass. }}$ Torrefied biomass showed similar combustible gas production than the corresponding raw biomass under the conditions studied, but it gave slightly higher $\mathrm{H}_{2}$ production and efficiency results. Possible correlations of the gasification performance
\end{abstract}

\footnotetext{
* Corresponding author. Tel.: +34985 1190 90; Fax: +34 985297662

E-mail address: victoria.gil@ incar.csic.es (M. V. Gil)
} 
parameters with biomass properties were also analyzed. The results showed positive effects of biomass volatile matter content, $\mathrm{C}$ content and high heating value (HHV) on the $\mathrm{CO}$ and combustible gas contents, calorific value of the product gas, as well as gas and energy yields.

Keywords: Biomass properties; Air-steam gasification; Bubbling fluidized bed; Hydrogen; Syngas

\section{Introduction}

Fossil fuels currently provide around $81 \%$ of world's energy demand [1], but their expected future shortage, price instability and environmental concerns regarding greenhouse gas emissions and climate change encourage to find a sustainable alternative to substitute them as main energy source. In this context, hydrogen appears as a promising option, since it provides a highly energetic [2] and clean combustion [3]. As hydrogen does not exist isolated in nature, it is mainly obtained by steam reforming of fossil fuels, mostly natural gas [4], coupled to a water gas shift (WGS) reaction and an adsorption unit [5]. As a promising option of feedstock, biomass is a neutral $\mathrm{CO}_{2}$ and renewable carbon source [6]. It is also a plentiful and cheap resource [7] that can be converted in solid, liquid or gaseous products with high efficiency by different thermochemical processes, such as pyrolysis and gasification [8]. Arregi et al. [9] in their review about thermochemical routes for hydrogen production from biomass remark the gasification of biomass and the reforming of the bio-oil produced by biomass pyrolysis as the most researched pathways for hydrogen generation from renewable sources.

Thus, gasification is one of the most attractive technologies to convert biomass into valuable fuels within the current energy scenario, which strongly requires a clean and sustainable energy future. It is a thermochemical process that consists of the partial oxidation of organic solid matter, which is converted on a mixture of solid (char, particles), liquid (tar) and gaseous $\left(\mathrm{H}_{2}, \mathrm{CO}, \mathrm{CH}_{4}, \mathrm{CO}_{2}, \mathrm{C}_{\mathrm{x}} \mathrm{H}_{\mathrm{y}}, \mathrm{H}_{2} \mathrm{~S}\right)$ [10] products whose quality and distribution depend on the selected feedstock, oxidizing agent (air, $\mathrm{O}_{2}$, steam, carbon dioxide or their mixtures), reactor type and reaction conditions (temperature, pressure, residence time) [11]. Gasification is a complex process which involves multiple stages and reactions, including drying, pyrolysis and gasification steps [12]. During 
pyrolysis, devolatilization takes place, larger hydrocarbons break down to smaller ones, and biomass thermally decomposes into char and gas products. In the gasification step, the gas and char products of the preceding pyrolysis step react with oxygen or steam to form mainly $\mathrm{CO}, \mathrm{CO}_{2}, \mathrm{CH}_{4}$ and $\mathrm{H}_{2}$. The molecular structure of the gas and char can be then reformed through a series of reactions such as carbon oxidation, Boudouard, water gas, WGS or methanation [13]. The main reactions that may occur during the air-steam gasification process are represented in Eqs. (1)-(8):

Oxidation:

$$
\begin{array}{ll}
\mathrm{C}_{(\mathrm{s})}+\mathrm{O}_{2} \leftrightarrow \mathrm{CO}_{2} & \mathrm{AH}^{0}=-394 \mathrm{~kJ} / \mathrm{mol} \\
\mathrm{C}_{(\mathrm{s})}+1 / 2 \mathrm{O}_{2} \leftrightarrow \mathrm{CO} & \mathrm{AH}^{0}=-123 \mathrm{~kJ} / \mathrm{mol}
\end{array}
$$

Boudouard:

$$
\mathrm{C}_{(\mathrm{s})}+\mathrm{CO}_{2} \leftrightarrow 2 \mathrm{CO} \quad \mathrm{AH}^{0}=+172 \mathrm{~kJ} / \mathrm{mol}
$$

Water gas:

$$
\begin{array}{ll}
\mathrm{C}_{(\mathrm{s})}+\mathrm{H}_{2} \mathrm{O} \leftrightarrow \mathrm{CO}+\mathrm{H}_{2} & \mathrm{AH}^{0}=+131 \mathrm{~kJ} / \mathrm{mol} \\
\mathrm{C}_{(\mathrm{s})}+2 \mathrm{H}_{2} \mathrm{O} \leftrightarrow \mathrm{CO}_{2}+2 \mathrm{H}_{2} & \mathrm{AH}^{0}=+77 \mathrm{~kJ} / \mathrm{mol}
\end{array}
$$

Methanation:

$$
\mathrm{C}_{(\mathrm{s})}+2 \mathrm{H}_{2} \leftrightarrow \mathrm{CH}_{4} \quad \mathrm{AH}^{0}=-87 \mathrm{~kJ} / \mathrm{mol}
$$

Water gas shift:

$$
\mathrm{CO}+\mathrm{H}_{2} \mathrm{O} \leftrightarrow \mathrm{CO}_{2}+\mathrm{H}_{2} \quad \mathrm{AH}^{0}=-41 \mathrm{~kJ} / \mathrm{mol}
$$

Steam reforming:

$$
\mathrm{CH}_{4}+\mathrm{H}_{2} \mathrm{O} \leftrightarrow \mathrm{CO}+3 \mathrm{H}_{2} \quad \mathrm{AH}^{0}=+206 \mathrm{~kJ} / \mathrm{mol}
$$

Bubbling fluidized bed reactors (BFBRs) present high potential for biomass gasification due to their optimum gas/solid contact, good degree of mixing, enhanced heat and mass transfer, good temperature control and flexibility in feedstock. They are also able to work at an intermediate temperature range $\left(700-900^{\circ} \mathrm{C}\right)$, which is adequate for biomass gasification [14, 15]. Thus, bubbling fluidized bed reactors currently mean a very promising option for hydrogen production from biomass gasification. Several works focused on biomass gasification in BFBRs with the objective of producing hydrogen can be found in literature. Fremaux et al. [16] conducted an experimental study to obtain a hydrogen-rich gaseous stream from the steam gasification of wood residue in a researchscale reactor. They evaluated the influence of steam to biomass ratio (SBR), temperature, time duration of experiment and fuel particle size on hydrogen and tar productions. They 
found positive effects on $\mathrm{H}_{2}$ production when steam or temperature were increased, but negative influence when the particle size was increased. Karatas and Akgun [13] compared the influence of the SBR and the stoichiometric ratio (SR) on the $\mathrm{CO}, \mathrm{H}_{2}, \mathrm{CH}_{4}$ and $\mathrm{CO}_{2}$ concentrations during air and steam gasification of walnut and pistachio shells, concluding that the lower heating value (LHV) of the gaseous product stream was hardly affected by the SBR. Gil et al. [17] tested the influence of temperature, steam/ $\mathrm{O}_{2}$ and $\left(\mathrm{H}_{2} \mathrm{O}+\mathrm{O}_{2}\right) /$ biomass ratios on gas and tar compositions during pine wood chips gasification in a pilot plant. Optimum conditions were found as $800-860^{\circ} \mathrm{C}$, gasifying agent/biomass ratio of $0.8-1.2 \mathrm{~kg} / \mathrm{kg}$ daf and steam $/ \mathrm{O}_{2}$ of $3 \mathrm{~mol} / \mathrm{mol}$. Ghani et al. [18] evaluated the influence of temperature $\left(700-900^{\circ} \mathrm{C}\right)$ and SR (0.16-0.46) during bench-scale air gasification of coconut coir and palm kernel shell. Temperature favored the hydrogen production, while other parameters such as fluidizing velocity and feed load showed only minor effects on hydrogen yield.

The gasification process of rice husk was evaluated in a bubbling fluidized bed gasifier by Xiong et al. [19] and Yaghoubi et al. [20]. A kinetic model was employed to simulate the process. The results showed positive effects of the temperature on the gas heating value and gasifier efficiency, whereas the equivalence ratio presented an adverse impact on the heating value of the outlet gas. Steam was found to be more appropriate gasification agent for hydrogen production than air, while temperatures of $800-820^{\circ} \mathrm{C}$ were optimum for hydrogen production. Nam et al. [21] studied the pressurized air gasification of hardwood pellets in a pilot scale bubbling fluidized bed reactor, obtaining the highest gas heating value at the lowest equivalence ratio of 0.23 . Higher temperature and equivalence ratio promoted a reduction in tar yield, while a higher pressure led to an increase in $\mathrm{CH}_{4}$ and $\mathrm{H}_{2}$ productions.

Campoy et al. [22] tested the air-steam autothermal gasification of wood pellets in an adiabatic bubbling-fluidized bed pilot plant, and they reached an increase of $20 \%$ in the gasification efficiency when optimized steam conditions were used. Lv et al. [23] demonstrated that the production of $\mathrm{H}_{2}$ during pine sawdust air-steam gasification was directly influenced by the temperature of operation and inversely by the biomass particle size and SR. Barisano et al. [24] studied the gasification of almond shells in a $1000 \mathrm{~kW}_{\text {th }}$ pilot plant based on a bubbling fluidized bed reactor with internal recirculation at atmospheric pressure and temperatures between 820 and $880{ }^{\circ} \mathrm{C}$. Steam/ $/ \mathrm{O}_{2}$ and enriched 
air (35 and $50 \mathrm{wt} . \% \mathrm{O}_{2}$ ) were used as oxidizing agents. The best results for producing a suitable product gas were obtained during gasification with enriched air at the lowest enrichment ratio. Eucalyptus gasification was investigated by using different gasifying agents (air, air-steam and $\mathrm{O}_{2}$-steam) by de Sales [25]. They found that the use of saturated steam increased the concentration of $\mathrm{H}_{2}$ despite its low temperature, due to the beneficial presence of $\mathrm{O}_{2}$. Air-steam gasification of citrus peel residues from citrus juice manufacturing was also studied in a fluidized bed reactor for hydrogen rich syngas production by Prestipino et al. [26]. The highest hydrogen yield was found at $750{ }^{\circ} \mathrm{C}$, while the cold gas efficiency reached the maximum value at $850{ }^{\circ} \mathrm{C}$ due to the higher concentration of carbon monoxide.

Corella et al. [27] studied the steam gasification of pine sawdust in a pilot plant using dolomite and a fluid catalytic cracking catalyst, which showed to be effective for the tar cracking and for the reforming of the product gas, hence improving the hydrogen production. The gasification of wood residue integrated with $\mathrm{CO}_{2}$ capture for high-purity hydrogen production has also been investigated using $\mathrm{CaO}$ as sorbent by modelling the process using ASPEN PLUS [28]. The $\mathrm{H}_{2}$ concentration from the biomass gasification process with $\mathrm{CO}_{2}$ capture was found to be always higher than that from the conventional process when a carbonation temperature lower than $750{ }^{\circ} \mathrm{C}$ was used. Tian et al. [29] studied the air-steam gasification of biomass in a fluidized bed. To enhance the yield of produced syngas and reduce its tar content by cracking, limestone, calcined dolomite, and olivine were used as catalysts. Calcined dolomite was proved to be more effective for gas production and tar destruction. The maximum mole fraction of $\mathrm{H}_{2}$ obtained was $49.1 \mathrm{vol} \%$ at $1000^{\circ} \mathrm{C}$.

Steam gasification of municipal solid wastes (MSW) has also been studied in a bubbling fluidized bed reactor using numerical models and validating the results with data from the literature for biomass substrates [30]. MSW presented lower carbon conversion, gas yield and cold gas efficiency with higher tar content. However, the pre-existing collection and transportation infrastructure currently available for municipal waste does not exist for the compared biomass resources, which makes it a promising alternative, due to the environmental advantages it entails, in comparison with the traditional landfilling of these wastes. 
Therefore, biomass gasification has been studied in literature using fluidized bed reactors at different scales, from laboratory to pilot scale. Most of the biomass gasification studies have focused on gasification of wood, although some research has also been performed on gasification of agricultural biomass (rice husk, wheat straw, citrus residues or almond, peanut, walnut and pistachio shells) and municipal wastes. The published studies on gasification of other types of biomass wastes in bubbling fluidized beds are more scarce. On the other hand, the studies in the literature have mainly focused on the effect of some operating variables on the gasification performance of different biomass resources. Thus, the combined effect of the different properties of the biomass samples, gasification conditions (temperature, gasifying agent) and reactor characteristics have conducted to a great variability in the reported results. This makes it difficult to draw comparisons between biomasses because the results are masked by the variations in the operating conditions of the process. The effect of the type of feedstock on the gasification process has hardly been considered in literature. However, the necessity of processing different feedstocks locally generated or produced in the same gasifier, which should be flexible concerning the fuel input requirements, has been pointed out [31]. There are very few studies in literature that focused on the comparison of the gasification performance of several biomass samples [31,32]. However, these studies lacked the evaluation of possible correlations between the gasification results and the biomass characteristics, due to biomass and organic residues are complex materials, and the interactions between their properties are intrinsically very complicated, which makes it difficult to relate the gasification results with the biomass features.

Therefore, in the present work 10 biomass samples of different characteristics and origin, including woody biomass, forest and food industry wastes, as well as torrefied biomass, have been gasified under similar conditions with the objective of obtaining comparable results and trying to establish possible relationships between the biomass properties and the gasification performance parameters. This has not previously been reported in literature to the best of the authors' knowledge, and it may be another relevant contribution of this work. Furthermore, torrefaction, as pretreatment of raw biomass, is becoming a leading technology to upgrade biomass quality and facilitate its industrial use [33]. However, the gasification process of torrefied biomass in fluidized bed reactors has been very hardly studied in literature [14, 34]. 
The biomass samples used in this study are lignocellulosic biomass wastes, which are considered as the most suitable alternative feedstocks in order to establish a sustainable energy system without competition with human and animal food and soil exhaustion [35]. Further environmental and economic advantages can be reached if syngas is produced by residues or wastes [26]. Gasification is a promising option for the biomass treatment since the gaseous product can be directly used as fuel or as an intermediate product for the production of fuels and chemicals. Gasification plants need to be established in the regions where biomass is available to reduce the costs for the transportation of the raw material or the formed gaseous products. Important advantages of the biomass resources used in the present work are that they are locally produced and their prices are low due to their waste nature. These characteristics make these biomasses a relevant alternative option for sustainable $\mathrm{H}_{2}$ production by gasification. A disadvantage of the use of biomass wastes as fuel is its seasonal nature, which limits its availability to specific periods during the year. However, fluidized bed gasification is a versatile thermochemical process that may be designed to operate with a variety of feedstocks, derived from different species of variable nature.

Although some of the referenced studies employed steam as gasifying agent, most of them employed a blend of air (or oxygen) and steam, since the addition of some amount of oxygen to the gasifier implies that the biomass is partially oxidized for supplying heat to the endothermic biomass gasification reaction. However, if oxygen is directly mixed with steam instead of air, the cost of the process greatly increases due to the high cost of pure oxygen. Thus, the aim of the present study was focused on the evaluation of the air-steam gasification process in a pilot-scale bubbling fluidized bed gasifier using a wide range of biomass types as feedstock for producing sustainable hydrogen and/or syngas. The effect of the main operating variables on the process performance was evaluated in order to provide a better understanding of the operation of the fluidized bed plant used for production of hydrogen from biomass resources. Thus, the gasification operating parameters, such as temperature, steam to air ratio (S/A) in the gasifying agent and SR, were evaluated using pine kernel shell (PKS) samples. Furthermore, the gasification conditions with the best results were used to test the gasification process on a number of different biomasses. Finally, a novel attempt to correlate the biomass properties with the gasification performance parameters was carried out. The results are expected to provide 
a useful knowledge focused towards a more sustainable local energy production and/or an effective valorization of biomass wastes.

\section{Material and methods}

\subsection{Biomass characterization}

Ten lignocellulosic biomass samples from different origins were selected to study the airsteam gasification of biomass resources. Softwood (pine sawdust -PIN-) and hardwood (chestnut sawdust -CHE-) biomass samples, together with their torrefied products obtained by heating at $280^{\circ} \mathrm{C}$ for $1 \mathrm{~h}$ in a Nabertherm RSR horizontal tubular rotary furnace (PINT and CHET, respectively), were tested. Five seasonal wastes, provided by local Spanish food industries, were also selected: almond shells (AS), cocoa shells (CS), grape pomace (GP), olive stones (OS) and pine kernel shells (PKS). In addition, a forest waste, pine cone leaf (PCL), traditionally employed as heat source in heaths and stoves in rural environments in Northern Spain, was chosen for the gasification tests.

The samples were air-dried at room temperature for $72 \mathrm{~h}$, ground using a Retsch SM 2000 cutting mill and sieved to a particle size of $0.1-1 \mathrm{~mm}$. Ultimate and proximate analyses, as well as higher heating value (HHV), were determined for the characterization of the biomasses. Mass percentage of the fixed carbon (FC) and oxygen contents were calculated by difference in a dry basis, using Eq. (9) [36] and Eq. (10) [37], respectively.

$\mathrm{FC}(\%)=100-(\mathrm{VM}+\mathrm{Ash})$

$\mathrm{O}(\%)=100-(\mathrm{Ash}+\mathrm{C}+\mathrm{N}+\mathrm{H}+\mathrm{S})$

where VM is the volatile matter content. The biomass characterization results are shown in Table 1.

Table 1. Ultimate, proximate and high heating value analyses, as well as H/O ratio and He density for the studied biomass samples

\begin{tabular}{|c|c|c|c|c|c|c|c|c|c|c|c|c|}
\hline \multirow{3}{*}{ Sample } & \multirow{2}{*}{\multicolumn{5}{|c|}{$\begin{array}{l}\text { Ultimate analysis } \\
(\mathrm{wt} \%, \mathrm{db})\end{array}$}} & \multicolumn{4}{|c|}{ Proximate analysis } & \multirow{3}{*}{$\begin{array}{l}\text { HHV } \\
\text { (MJ/kg, db) }\end{array}$} & \multirow{3}{*}{$\begin{array}{l}\mathrm{H} / \mathrm{O} \\
\text { ratio }\end{array}$} & \multirow{3}{*}{$\begin{array}{l}\text { He density } \\
\left(\mathrm{g} / \mathrm{cm}^{3}\right)^{\mathrm{b}}\end{array}$} \\
\hline & & & & & & \multirow{2}{*}{$\begin{array}{l}\text { (wt\%) } \\
\text { MC }\end{array}$} & \multicolumn{3}{|c|}{$(\mathrm{wt} \%, \mathrm{db})$} & & & \\
\hline & $\mathbf{C}$ & $\mathbf{N}$ & $\mathbf{H}$ & $\mathbf{S}$ & $\mathbf{O}^{\mathrm{a}}$ & & Ash & VM & $\mathbf{F C}^{\mathrm{a}}$ & & & \\
\hline AS & 49.44 & 0.31 & 5.85 & 0.05 & 42.90 & 6.5 & 1.45 & 78.9 & 19.6 & 19.565 & 2.16 & 1.252 \\
\hline CHE & 50.22 & 0.34 & 5.55 & 0.01 & 43.41 & 8.4 & 0.47 & 81.2 & 18.3 & 19.109 & 2.03 & 1.268 \\
\hline CHET & 51.30 & 0.40 & 5.40 & 0.02 & 42.59 & 8.2 & 0.29 & 80.0 & 19.7 & 19.588 & 2.01 & 1.275 \\
\hline CS & 47.96 & 2.74 & 5.93 & 0.21 & 35.26 & 6.7 & 7.90 & 70.4 & 21.7 & 19.067 & 2.67 & 1.156 \\
\hline GP & 45.50 & 1.82 & 5.05 & 0.17 & 34.73 & 11.6 & 12.73 & 67.6 & 19.7 & 18.682 & 2.31 & 1.210 \\
\hline OS & 51.21 & 0.29 & 6.01 & 0.03 & 41.88 & 4.3 & 0.58 & 81.5 & 17.9 & 20.511 & 2.28 & 1.241 \\
\hline PCL & 52.89 & 0.44 & 6.06 & 0.03 & 39.46 & 10.1 & 1.12 & 76.5 & 22.4 & 20.976 & 2.44 & 1.237 \\
\hline PIN & 51.02 & 0.27 & 6.04 & 0.02 & 42.23 & 9.6 & 0.42 & 85.1 & 14.5 & 19.904 & 2.27 & 1.241 \\
\hline PINT & 54.52 & 0.39 & 5.66 & 0.02 & 39.01 & 6.4 & 0.40 & 78.6 & 21.0 & 21.568 & 2.30 & 1.257 \\
\hline PKS & 52.32 & 0.62 & 6.21 & 0.05 & 38.99 & 9.4 & 1.81 & 78.4 & 19.8 & 20.767 & 2.53 & 1.221 \\
\hline
\end{tabular}

db: dry basis; MC: moisture content; VM: volatile matter; FC: fixed carbon; HHV: higher heating value.

${ }^{a}$ Determined by difference.

${ }^{\mathrm{b}} \mathrm{He}$ density $=1.534-0.05196 \cdot[\% \mathrm{H}]+0.0007375 \cdot[\% \mathrm{O}]-0.02472 \cdot[\% \mathrm{~N}]+0.0003853 \cdot[\% \mathrm{~S}]$ (percentages in dry ash-free basis) $[38]$ 


\subsection{Experimental plant}

The gasification plant (PID Eng\&Tech) used in this work consists of an atmospheric pressure bubbling fluidized bed reactor. Fig. 1 shows the flow diagram of the experimental facility. The plant comprises a double-hopper feeding system, a pre-heated gas inlet, a gasification reactor with freeboard, an outlet gas double cyclone cleaning system, a tar trap and a condenser, as well as control and measuring systems.

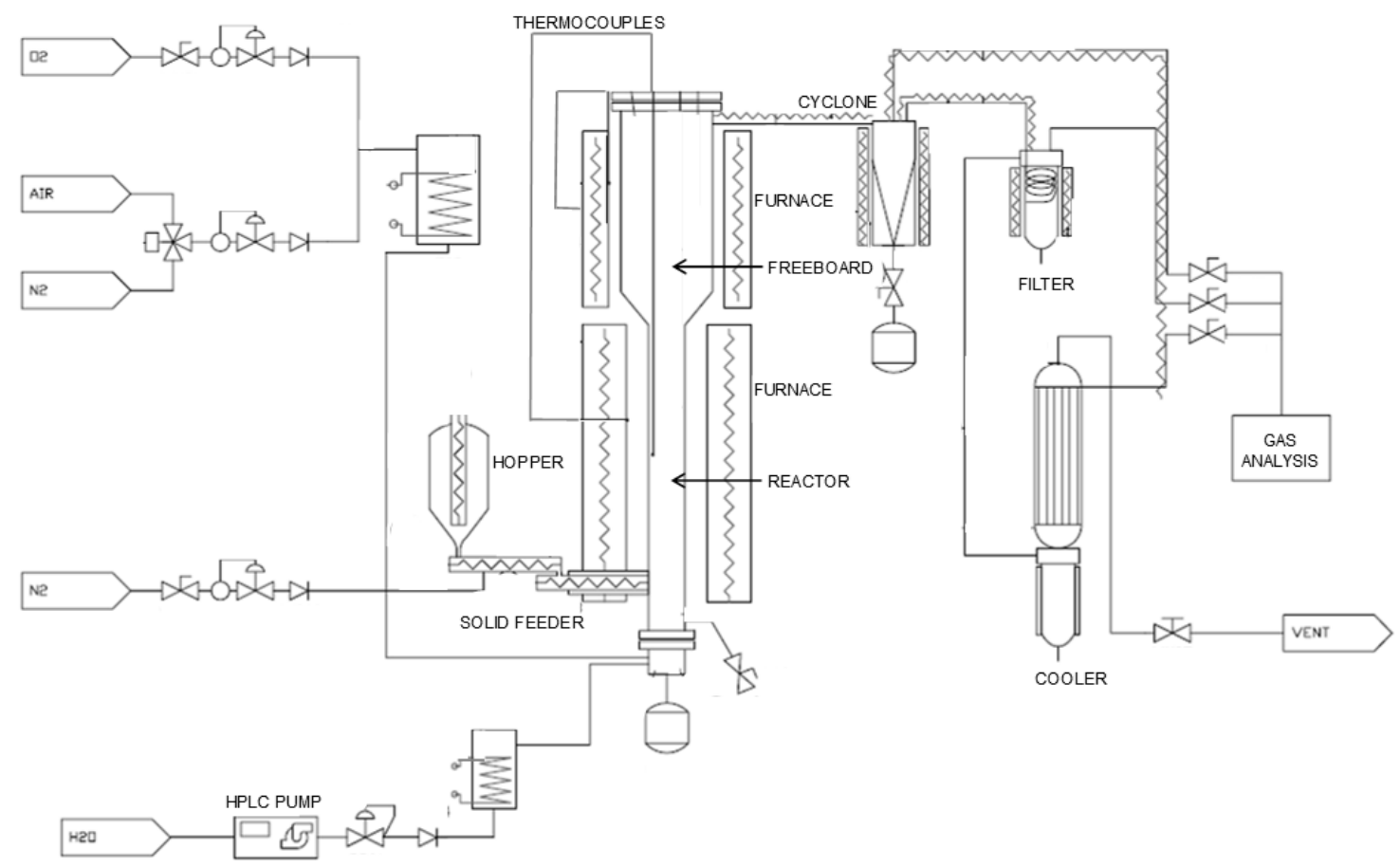

Fig. 1. Flow diagram of the gasification plant used in the experimental work.

The gasification reactor is a SS310 cylinder with a height of $1 \mathrm{~m}$ and an inner diameter of $77 \mathrm{~mm}$, which ends in a $52 \mathrm{~mm}$ long and $133 \mathrm{~mm}$ diameter freeboard. Both the reactor and freeboard are surrounded by three independent electrical furnaces that can supply a maximum power of $22 \mathrm{~kW}$, which is sufficient to raise the temperature of the reactor wall to $950{ }^{\circ} \mathrm{C}$. The bed material in the fluidized reactor consisted of $1 \mathrm{~kg}$ of coal ash (212-710 $\mu \mathrm{m})$, which assured stable fluidization and good heat transfer.

The fuel feeding system includes a main storage hopper $(10 \mathrm{~L})$, which is communicated by an auger $(\varnothing=20 \mathrm{~mm})$ with a smaller secondary one. This system limits the fuel burning risk in the main hopper. The revolution speed of the main hopper's auger needs to be calibrated for each different biomass sample so that it accurately provides the mass 
flow of fuel required in each experiment. A water cooled secondary auger $(\varnothing=20 \mathrm{~mm})$ directly introduces the fuel sample into the fluidized bed reactor at approximately $6 \mathrm{~cm}$ above the bottom of the reactor. This turns slightly faster than the primary auger, avoiding the biomass accumulation in the secondary hopper and inlet tube, which prevents burning, melting and slagging events in the sections close to the reactor. A fixed stream of 1.0 $\mathrm{NL} / \mathrm{min}$ of $\mathrm{N}_{2}$ is fed into the main hopper by a Bronkhorst High-Tech mass flow controller to slightly increase the internal pressure, restricting reverse gas flow from the reactor, and to provide an inert atmosphere that limits combustion risks inside the fuel store.

Air required for fluidization and partial oxidation reaction is supplied directly to the reactor by a second mass flow controller that can provide up to $200 \mathrm{NL} / \mathrm{min}$ of overall gas. A Wilson 307 piston pump feeds in the required mass flow of liquid water to the reactor, which is continuously heated up to $400{ }^{\circ} \mathrm{C}$ to assure a condensate-free flow of steam into the reactor. The mix of reactive gases involved in the gasification process is pre-heated by a $4.5 \mathrm{~kW}$ Watrod SS310 circulation heater.

When the product gas leaves the reactor, fly ashes and solid particles generated during the experiment are firstly retained in a cyclone and then in a $100 \mu \mathrm{m}$ pore diameter ceramic filter (PID Eng\&Tech). This section is heated at $400{ }^{\circ} \mathrm{C}$ to avoid tar condensation in pipes. The outlet stream is directed to a heat exchanger where water and heavy tars condense and are separated from the gas stream. A portion of the gas stream goes through a cold trap filled with isopropyl alcohol and distilled water that captures the lighter tars. The cleaned gases are sent to a battery of analyzers where the main gases $\left(\mathrm{H}_{2}, \mathrm{CO}, \mathrm{CH}_{4}\right.$, $\mathrm{CO}_{2}$ and $\mathrm{O}_{2}$ ) are measured in terms of volume percentage on a dry basis, while $\mathrm{N}_{2}$ is estimated by difference. A Rosemount HYDROS 100 analyzer from Emerson is used to measure $\mathrm{H}_{2}$ by thermal conductivity, a Rosemount OXYNOS 100 analyzer from Emerson measures $\mathrm{O}_{2}$ using a paramagnetic sensor, and Rosemount BINOS 100 analyzers from Emerson are used to measure $\mathrm{CO}, \mathrm{CO}_{2}$ and $\mathrm{CH}_{4}$ by infrared photometry.

\subsection{Gasification experiments}

The pilot plant used in this work is a highly versatile bubbling fluidized bed gasifier that can be easily adapted to use biomass samples of very different nature and variable gasifying agents, thus allowing the study of a wide range of stoichiometric ratios (SR), steam to biomass ratios (SBR) and steam to air ratios (S/A). SR is defined as the air to 
fuel weight ratio used divided by the air to fuel weight ratio of stoichiometric combustion. These ratios can be calculated as follows [39-41]:

$\mathrm{SR}=\frac{(\text { Oxygen } / \text { fuel })_{\text {used }}}{(\text { Oxygen } / \text { fuel })_{\text {stoichiometric }}}$

$\mathrm{SBR}=\frac{\text { Total water supplied }(\mathrm{g} / \mathrm{min})}{\text { Fuel supplied to } \mathrm{SR}(\mathrm{g} / \mathrm{min})}$

$\mathrm{S} / \mathrm{A}=\frac{\text { Total water supplied }(\mathrm{g} / \mathrm{min})}{\text { Total air supplied }(\mathrm{g} / \mathrm{min})}$

Firstly, gasification experiments were carried out using pine kernel shell (PKS) in order to evaluate the effect of the gasification temperature $\left(700,800,900{ }^{\circ} \mathrm{C}\right)$, steam to air ratio $(\mathrm{S} / \mathrm{A}=70 / 30,50 / 50,25 / 75,10 / 90)$ and stoichiometric ratio $(\mathrm{SR}=0.13,0.25)$ on the gasification process. Furthermore, nine additional biomass samples of different origin were gasified at the best experimental conditions found from the previous experiments. For all the experiments, the same total inlet gas flow rate has been used to keep the space residence time constant and to maintain similar fluidization conditions within the gasifier. The product gas composition was calculated on the basis of nitrogen-free and dry composition of the gas effluent. The gas flow rates of the species generated during the experiments were then calculated by means of a nitrogen balance, since the amount of nitrogen fed in and the composition of the nitrogen evolved are known. In addition, some representative molar gas ratios $\left(\mathrm{H}_{2} / \mathrm{CO}, \mathrm{H}_{2} / \mathrm{CO}_{2}, \mathrm{CO} / \mathrm{CO}_{2}\right.$ and $\left.\mathrm{H}_{2} / \mathrm{CH}_{4}\right)$ were calculated. From the gaseous emissions results, the gas yield $\left(\eta_{\text {gas }}\right)$ [24], the HHV of the gas obtained [42], the energy yield $\left(\eta_{\text {energy }}\right)$ and the cold-gas efficiency (CGE) [43] were determined as follows:

$$
\begin{aligned}
& \eta_{\text {gas }}\left(\mathrm{Nm}^{3} \text { gas } / \mathrm{kg}_{\text {biomass }}\right)=\frac{\dot{\mathrm{Q}}_{\text {outletgas }}}{\dot{m}_{\text {biomass }}} \\
& \mathrm{HHV}_{\text {gas }}\left(\mathrm{MJ} / \mathrm{Nm}^{3}\right)=\left(11.76 \cdot \mathrm{x}_{\mathrm{CO}}+11.882 \cdot \mathrm{x}_{\mathrm{H}_{2}}+37.024 \cdot \mathrm{x}_{\mathrm{CH}_{4}}\right) \cdot 10 / 1000 \\
& \eta_{\text {energy }}\left(\mathrm{MJ} / \mathrm{kg}_{\text {biomass }}\right)=\eta_{\text {gas }} \cdot \mathrm{HHV}_{\text {gas }} \\
& \operatorname{CGE~}(\%)=\eta_{\text {gas }} \cdot \frac{\mathrm{HHV}_{\text {gas }}}{\mathrm{HHV}_{\text {biomass }}}
\end{aligned}
$$

where $\dot{\mathrm{Q}}_{\text {outlet-gas }}$ is the volumetric flow of the outlet gas $\left(\mathrm{Nm}^{3} / \mathrm{h}\right)$, obtained by applying a balance to the inert gas $\left(\mathrm{N}_{2}\right), \dot{\mathrm{m}}_{\text {biomass }}$ is the biomass inlet mass flow in dry basis $(\mathrm{kg} / \mathrm{h})$, 
$\mathrm{x}_{\mathrm{i}}(\mathrm{vol} \%)$ represents the volumetric percentage of each component in the dry product gas, and $\mathrm{HHV}_{\text {biomass }}$ is the higher heating value of the raw biomass $(\mathrm{MJ} / \mathrm{kg})$.

\section{Results and discussion}

\subsection{Effect of temperature, S/A ratio and SR on biomass gasification}

The effect of the experimental conditions on the biomass gasification performance has been evaluated using the PKS sample. The gasification parameters studied were temperature $\left(700,800\right.$ and $\left.900{ }^{\circ} \mathrm{C}\right), \mathrm{S} / \mathrm{A}$ ratio $(10 / 90,25 / 75,50 / 50$ and 70/30) and SR (0.13 and 0.25$)$, which implied a SBR range from 0.04 to 1.85 . The temperature influence was determined carrying out experiments at 700, 800 and $900{ }^{\circ} \mathrm{C}$ keeping the S/A ratio equal to 70/30. The effect of the steam to air ratio was evaluated performing experiments using S/A values of 10/90, 25/75, 50/50 and 70/30, keeping the temperature at $900{ }^{\circ} \mathrm{C}$. All these experiments were repeated using SR values of 0.13 and 0.25 in order to analyze the effect of the stoichiometric ratio. Fig. 2 shows the $\mathrm{N}_{2}$-free composition of the product gas, hence removing the different effect of the dilution in $\mathrm{N}_{2}$ for the different experiments. $\mathrm{H}_{2}$ content in the product gas (Fig. 2a) increases with temperature and S/A ratio, while the $\mathrm{CO}$ (Fig. 2b), $\mathrm{CH}_{4}$ (Fig. 2c) and $\mathrm{CO}_{2}$ (Fig. 2d) contents slightly decrease with both temperature and S/A ratio. Higher temperature favors $\mathrm{H}_{2}$ production due to the endothermic steam reforming (Eq. (8)) and water gas (Eqs. (4) and (5)) reactions by shifting the chemical equilibrium towards the formation of products according to Le Chatelier's principle. Thus, higher temperatures promote the production of $\mathrm{H}_{2}$ mainly due to the enhancement of steam reforming of char and methane, leading to higher char conversion. On the other hand, the exothermic WGS reaction (Eq. (7)) could shift to the $\mathrm{CO}$ and $\mathrm{H}_{2} \mathrm{O}$ side at higher temperature, which would reduce the $\mathrm{H}_{2}$ production, although an increase in the reaction rate with temperature could favor it. Therefore, the overall $\mathrm{H}_{2}$ formation could be controlled by the competing water gas and steam methane reforming reactions with the WGS reaction [14]. The results shown in Fig. 2a indicate that the $\mathrm{H}_{2}$ production dominates over its consumption when temperature is increased under the studied conditions.

Regarding the $\mathrm{CH}_{4}$ content, a slight decrease with temperature was found (Fig. 2c). An increase in temperature causes higher devolatilization rates, which will produce a higher methane release during the first step of the gasification process. Moreover, higher 
temperatures favor, in turn, the endothermic steam methane reforming reaction, which consumes the released methane. Therefore, the effect of the increase in temperature has resulted in a slight decrease in the methane concentration in the outlet gas, as seen in Fig. 2c.
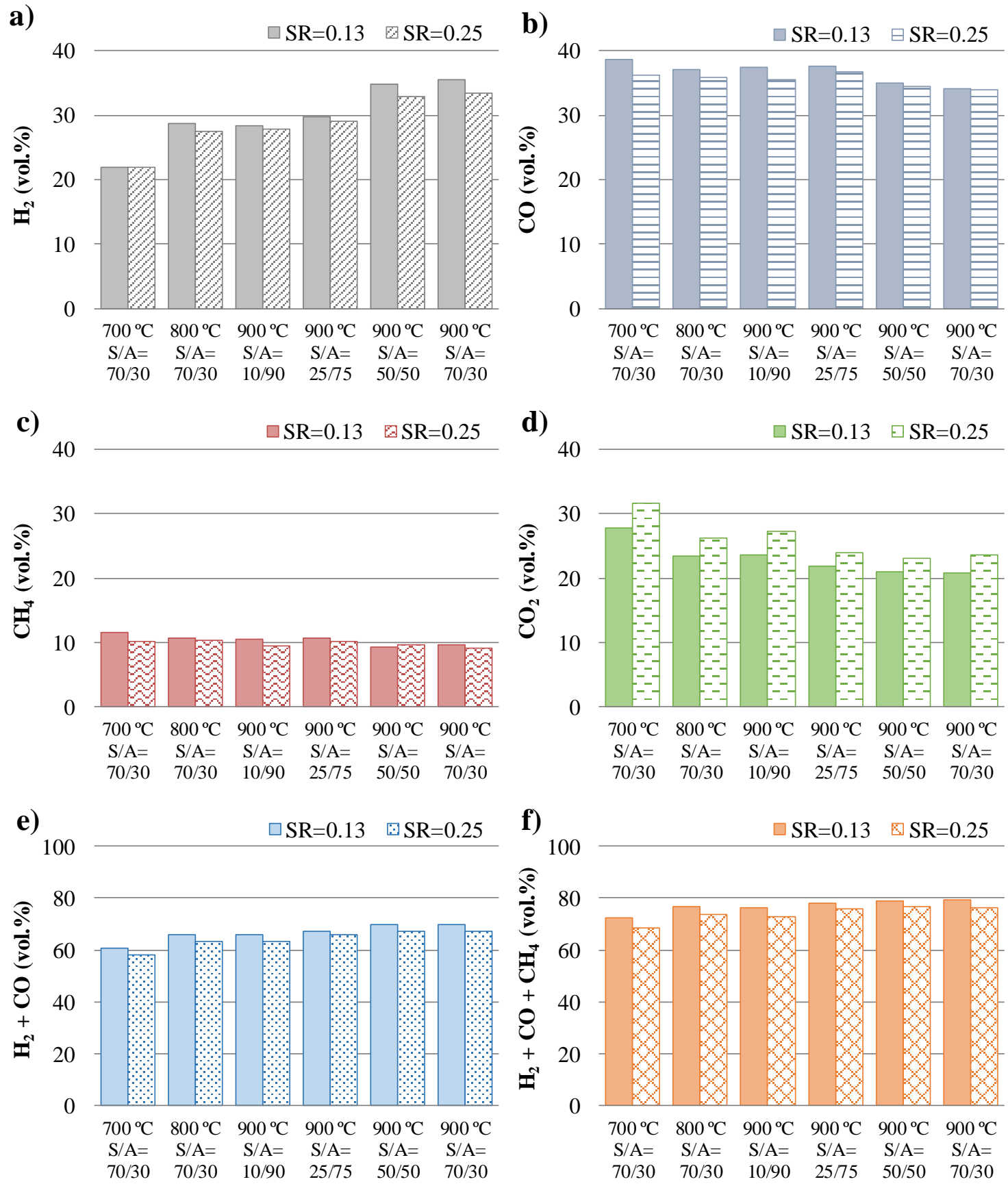

Fig. 2. $\mathrm{N}_{2}$-free composition of the product gas from the gasification of PKS as a function of temperature, steam to air ratio (S/A) in the gasifying agent and SR: (a) $\mathrm{H}_{2}$; (b) $\mathrm{CO}$; (c) $\mathrm{CH}_{4}$; (d) $\mathrm{CO}_{2}$; (e) syngas; and (f) overall combustible gas. 
In general, the $\mathrm{CO}$ concentration only varied in a small range along all the conditions studied, but a slight decrease with temperature can be detected, as shown in Fig. 2 b. Higher temperatures could reduce the partial oxidation reaction (Eq. (2)) producing less $\mathrm{CO}$, but $\mathrm{CO}$ could also be produced by the endothermic water gas (Eq. (4)), steam methane reforming (Eq. (8)) and Boudouard (Eq. (3)) reactions, while consumed by the WGS reaction. Therefore, its value will be the result of all these reactions. Thus, a slight decrease in the $\mathrm{CO}$ content with temperature could indicate that the WGS reaction occurred to higher extent with higher temperatures. This would be explained by the shift of the WGS equilibrium towards the consumption of $\mathrm{CO}$ due to a higher production of $\mathrm{CO}$ by the above mentioned reactions, together with an increase in its reaction rate with temperature [17].

On the other hand, Fig. $2 \mathrm{~d}$ shows a decrease in the $\mathrm{CO}_{2}$ content with temperature, which seems to indicate that at higher temperatures the $\mathrm{CO}_{2}$-consuming reactions would be more important than the WGS reaction. Thus, the WGS reaction alone would not explain the gas phase distribution, and other homogeneous and heterogeneous reactions would determine the concentrations of gas products. Endothermic reactions such as cracking and steam or dry reforming of tar may have been strengthened with the increase of gasification temperature, leading to the increase of $\mathrm{H}_{2}$ at the expense of $\operatorname{tar}, \mathrm{H}_{2} \mathrm{O}$ and $\mathrm{CO}_{2}$, as it has been suggested by some authors in the literature $[10,17]$.

Furthermore, the results indicate an improvement in the extent of the reforming and WGS reactions at the expense of the combustion reactions for higher steam contents in the gasifying agent. However, the gasification temperature in the studied range showed a more significant effect on biomass gasification than the steam content in the gasifying agent. Thus, the $\mathrm{H}_{2}$ concentration increased from $22 \mathrm{vol} \%$ at $700{ }^{\circ} \mathrm{C}$ to $35-36$ vol\% at $900{ }^{\circ} \mathrm{C}$, whereas the $\mathrm{H}_{2}$ content increased from 28 to $35-36$ vol\% between S/A ratios of 10/90 and 70/30, respectively. Moreover, the $\mathrm{H}_{2}$ concentration obtained at $800^{\circ} \mathrm{C}$ and $\mathrm{S} / \mathrm{A}=70 / 30$ is quite similar to that obtained at $900{ }^{\circ} \mathrm{C}$ and $\mathrm{S} / \mathrm{A}=10 / 90$, which means that seven times less steam in the oxidizing agent would be needed at higher temperature for obtaining similar results.

In relation to $\mathrm{SR}$, when a higher stoichiometric ratio is used $(\mathrm{SR}=0.25), \mathrm{H}_{2}, \mathrm{CO}$ and $\mathrm{CH}_{4}$ contents in the product gas show a slight decrease in relation to those obtained using $\mathrm{SR}=0.13$. Char oxidation reaction (Eq. (1)) is expected to be favored when using higher 
air content in the gasifying atmosphere, and it seems that $\mathrm{CO}$ formation by partial oxidation of the biomass carbonaceous matter (Eq. (2)) could have decreased. If a lower amount of $\mathrm{CO}$ is produced, less $\mathrm{H}_{2}$ and $\mathrm{CH}_{4}$ will be formed through WGS and methanation reactions and, therefore, $\mathrm{H}_{2}$ and $\mathrm{CH}_{4}$ show similar trends than $\mathrm{CO}$. On the contrary, slightly higher $\mathrm{CO}_{2}$ concentrations are produced with $\mathrm{SR}=0.25$ due to the role of the combustion reactions under higher air content in the gasifying atmosphere.

The $\left[\mathrm{H}_{2}+\mathrm{CO}\right]$ syngas (Fig. 2e) and the overall $\left[\mathrm{H}_{2}+\mathrm{CO}+\mathrm{CH}_{4}\right]$ combustible gas (Fig. 2f) follow identical tendency to that observed for the $\mathrm{H}_{2}$ concentration, its value increasing with temperature and S/A ratio, showing that their values are mainly associated to the $\mathrm{H}_{2}$ content in the product gas. Likewise, their values decrease with higher SR, as mentioned above. In fact, both $\mathrm{CO}$ and $\mathrm{CH}_{4}$ concentrations varied in small ranges of 34-39 vol\% and 9-11 vol\%, respectively, along the conditions studied.

Fig. 3 shows the $\mathrm{H}_{2} / \mathrm{CO}, \mathrm{H}_{2} / \mathrm{CO}_{2}, \mathrm{CO} / \mathrm{CO}_{2}$ and $\mathrm{H}_{2} / \mathrm{CH}_{4}$ molar ratios in the product gas, calculated from the flows of the different gases produced during the experiments. The $\mathrm{H}_{2} / \mathrm{CO}$ and $\mathrm{H}_{2} / \mathrm{CO}_{2}$ ratios (Figs. 3a and $3 \mathrm{~b}$, respectively) increase with temperature and steam concentration in the gasifying agent, which indicates enhanced steam reforming and WGS reactions due to the higher content of steam available or higher temperature. However, the concentration of $\mathrm{H}_{2}$ is similar to that of $\mathrm{CO}\left(\mathrm{H}_{2} / \mathrm{CO} \sim 1\right)$ only at the highest temperature and steam concentration in the gasifying agent studied. The $\mathrm{H}_{2} / \mathrm{CO}$ ratio in the outlet gas is important for further possible end uses of the syngas, although a low value of this ratio could be easily increased with downstream WGS processes. The $\mathrm{CO} / \mathrm{CO}_{2}$ ratio (Fig. 3c) slightly increases with temperature, but it decreases as the S/A ratio increases above 25/75, which shows the higher relative importance of the WGS reaction as more steam is available. The $\mathrm{H}_{2} / \mathrm{CH}_{4}$ ratio increases with both temperature and steam concentration in the gasifying agent. Although it is possibly caused to a large extent by the noticeable increase in the $\mathrm{H}_{2}$ concentration, an increase in the $\mathrm{CH}_{4}$ reforming reaction and/or a lower production of methane during the process would also be expected at higher temperatures or steam concentrations. On the other hand, the $\mathrm{H}_{2} / \mathrm{CO}$ ratio was not significantly affected by SR, while the $\mathrm{H}_{2} / \mathrm{CO}_{2}$ and $\mathrm{CO} / \mathrm{CO}_{2}$ ratios decrease when SR increases, showing the importance of the combustion reaction at the expense of the reforming reaction due to the higher content of air at higher stoichiometric ratio. 
a)

1.5

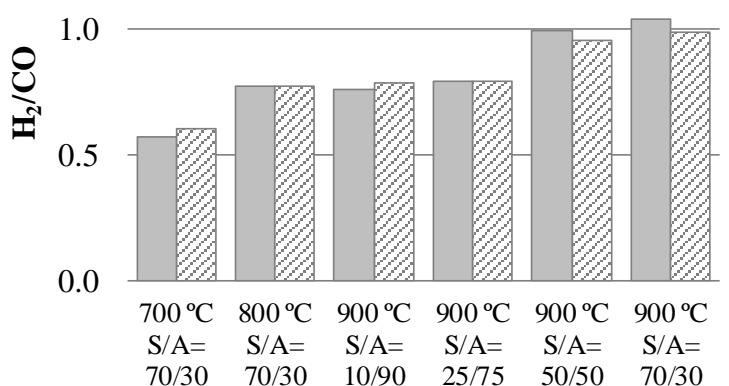

c)
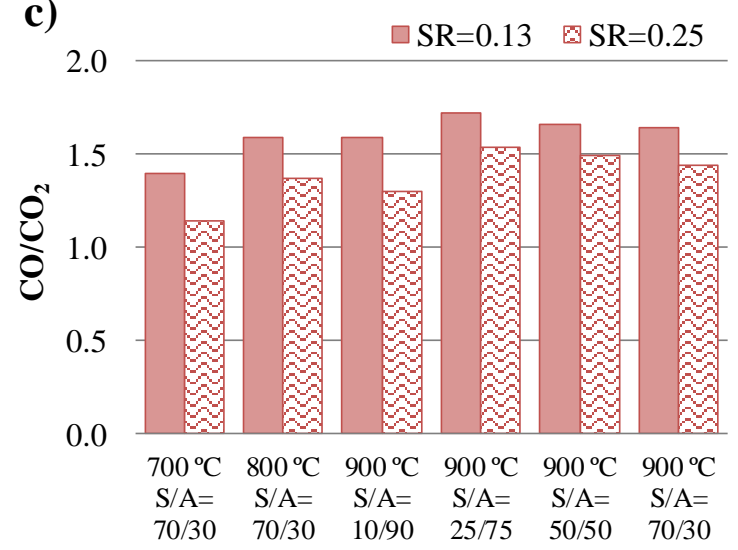

b)

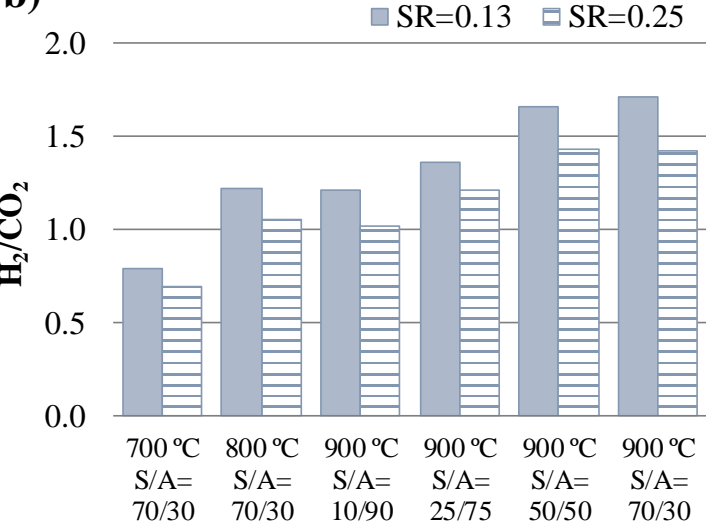

d)

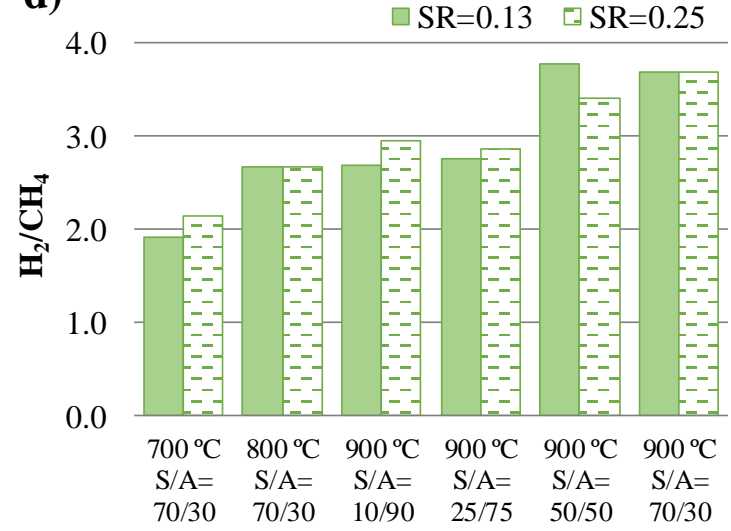

Fig. 3. $\mathrm{H}_{2} / \mathrm{CO}$ (a), $\mathrm{H}_{2} / \mathrm{CO}_{2}$ (b), $\mathrm{CO} / \mathrm{CO}_{2}$ (c) and $\mathrm{H}_{2} / \mathrm{CH}_{4}$ (d) molar ratios in the product gas from the gasification of PKS as a function of temperature, steam to air ratio (S/A) in the gasifying agent and SR.

The production of the main gases has also been expressed in mol of gas component produced per mol of dry biomass, since these data provide valuable information on the overall process as they take into account both the gas quality and the fuel conversion. The results are shown in Fig. 4. In general, these results indicate that the molar productions of $\mathrm{H}_{2}, \mathrm{CO}, \mathrm{CH}_{4}$ and $\mathrm{CO}_{2}$ increase with both temperature and steam concentration in the gasifying agent, which means a higher biomass conversion to gaseous products under higher temperature and steam conditions. A higher steam content mainly promotes the methane, char and tars steam reforming and the WGS reactions, while higher temperature enhances the endothermic water gas and steam reforming reactions. Moreover, an increase in SR from 0.13 to 0.25 also gives higher production of gases per mol of biomass. The combustion reactions associated to air prevent the temperature within the reactor to drop excessively, as well as to contribute to the production of $\mathrm{CO}$ and $\mathrm{CO}_{2}$ (via 
combustion, partial combustion and Boudouard reactions). Therefore, the net effect of air under the present experimental conditions is to improve the extension of devolatilization, tar cracking and gasification endothermic reactions, which enhances the product quality [41].

a)

$$
3.0
$$

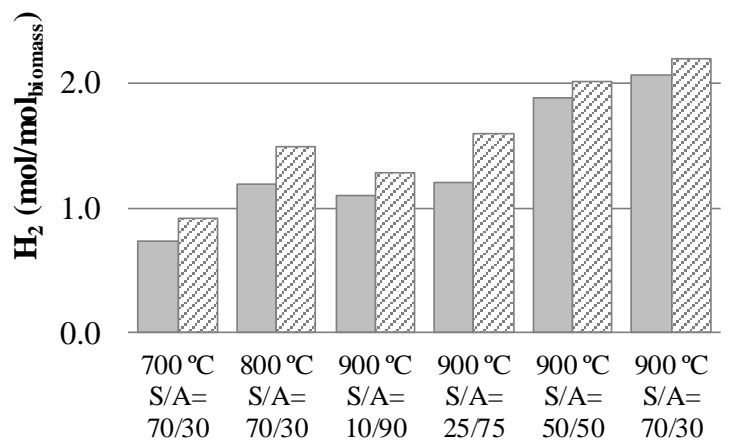

c)

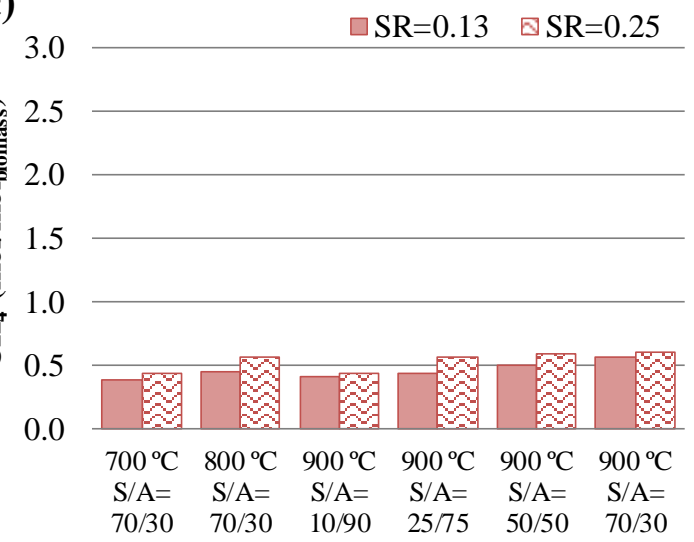

e)

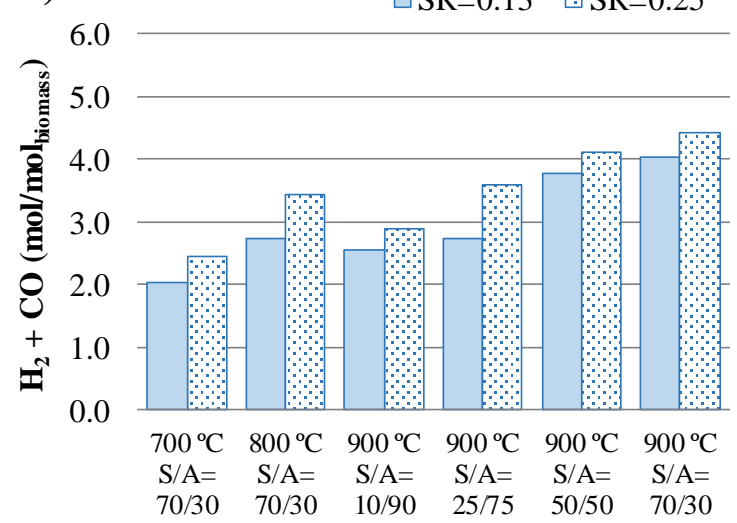

b) 3.0 $\square \mathrm{SR}=0.13 \square \mathrm{SR}=0.25$

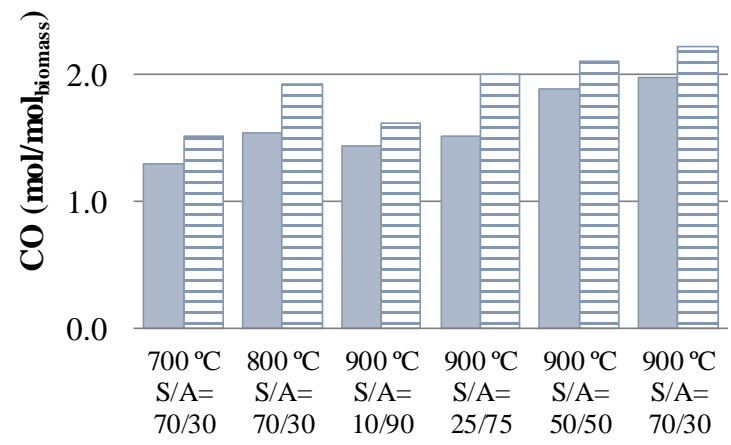

d) 3.0 $\square \mathrm{SR}=0.13 \square \mathrm{SR}=0.25$
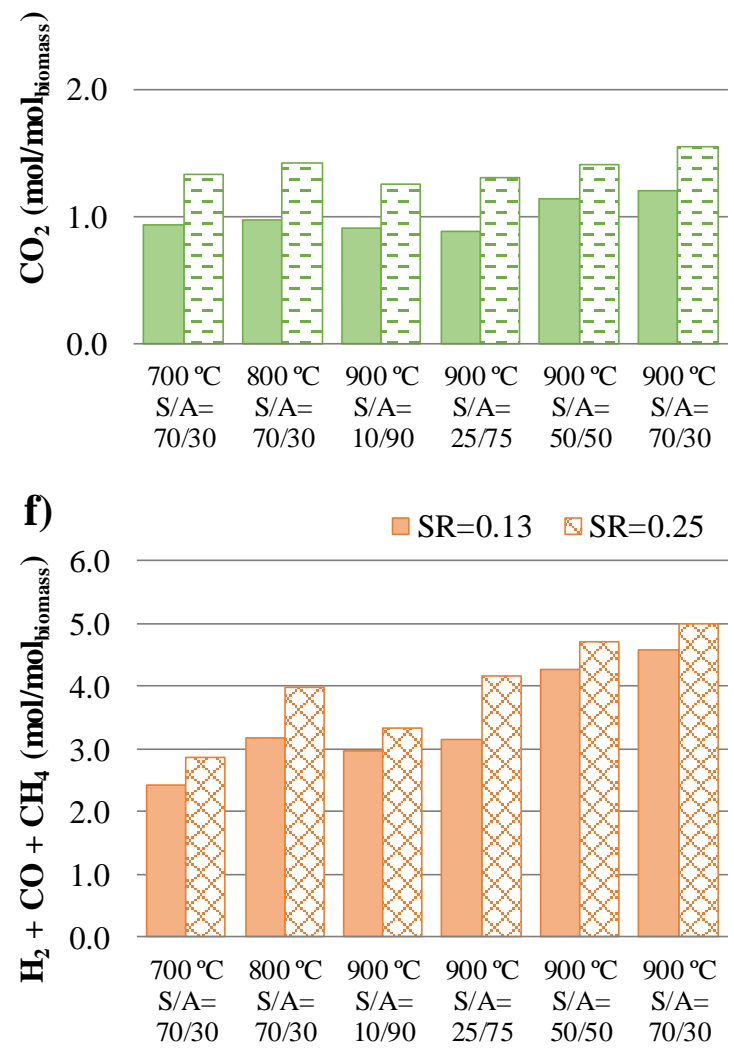

Fig. 4. Molar production of the main gases from the gasification of PKS as a function of temperature, steam to air ratio (S/A) in the gasifying agent and SR: (a) $\mathrm{H}_{2}$; (b) $\mathrm{CO}$; (c) $\mathrm{CH}_{4}$; (d) $\mathrm{CO}_{2}$; (e) syngas; and (f) overall combustible gas. 
The efficiency parameters for the gasification process are shown in Fig. 5. The gas yield, $\eta_{\text {gas }}$, increases with both temperature and S/A ratio (Fig. 5a), which agrees with the results for the molar production of gases shown in Fig. 4. It varied between 0.8 and 1.5

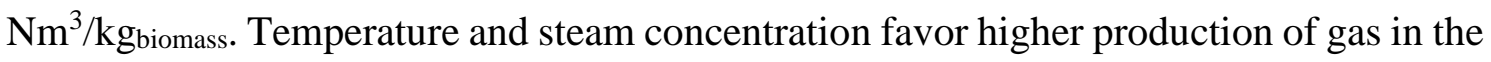
devolatilization step (faster at higher temperatures), an enhancement of gas production by char gasification with steam, and an increase in gas yield due to both steam reforming and cracking of hydrocarbons and tars [22]. A significant reduction in tar content in the produced syngas by steam gasification has also been reported in literature when using higher temperatures and steam concentrations $[16,17]$. The char yield has also been found to decrease with the increase in the gasification temperature due to an enhanced steam gasification of the char [34]. Moreover, the rate of reactions involved in the steam gasification process at lower temperatures $\left(700^{\circ} \mathrm{C}\right)$ seems to be extremely low compared with those at higher temperatures, such as $900{ }^{\circ} \mathrm{C}$, which results in lower char conversion and hence lower thermal efficiency [16].

Although the heating value of the product gas, $\mathrm{HHV}_{\mathrm{gas}}$, experiences a much lower change with the studied variables (10.6-12 $\mathrm{MJ} / \mathrm{Nm}^{3}$ ) (Fig. 5b), a significantly higher gas yield leads to higher energy yield (Fig. 5c) and cold gas efficiency (Fig. 5d) values as temperature and S/A ratio increase. Thus, $\eta_{\text {energy }}$ varied from 8.6 to $16.6 \mathrm{MJ} / \mathrm{kg}_{\text {biomass, }}$ while CGE varied between 41 and $80 \%$, under the different conditions studied.

On the other hand, an increase in SR from 0.13 to 0.25 increases the gas yield (Fig. 5a), in agreement with the increase in the production of gases shown in Fig. 4, but slightly decreases the heating value of the product gas (Fig. 5b) under the studied conditions, in agreement with the concentrations of combustible gases shown in Fig. 2. However, since the gas yield is considerably increased, the energy yield (Fig. 5c) and cold gas efficiency (Fig. 5d) show significantly higher values when using a SR of 0.25 . An increase in the gas yield with SR has also been reported in literature [22], showing the benefits of using a higher stoichiometric ratio for obtaining higher gas production. Furthermore, it should be pointed out that the SR may affect the gasification temperature, which could be increased with higher SR values. As reported by Lv et al. [23], the temperature controller of electric furnaces could not compensate the heat loss caused by biomass pyrolysis and steam reforming reactions and, hence, the operation temperature would not be kept constant in the lower part of the reactor. Thus, the actual temperature of the steam 
gasification would be higher when using higher SR values, and more gas and hydrogen, as well as CO, would be produced. This can explain a higher gas yield and a higher hydrogen yield as SR increases. A too small SR value lowers the reaction temperature, which is not favorable for biomass steam gasification, but a too large value would consume part of the produced $\mathrm{H}_{2}$ through the oxidation reaction. An optimum SR value of 0.23 has been reported in literature from air-steam gasification of pine sawdust in an atmospheric pressure fluidized bed aimed at obtaining a hydrogen-rich gas [23]. In the present study, a SR value of 0.25 clearly improves the gasification performance and it can be considered suitable for the biomass gasification process in the bubbling fluidized bed plant studied.

a)

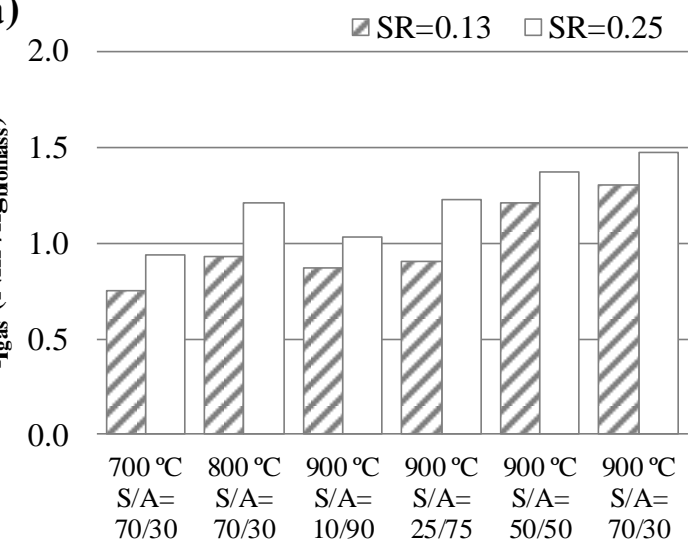

c)
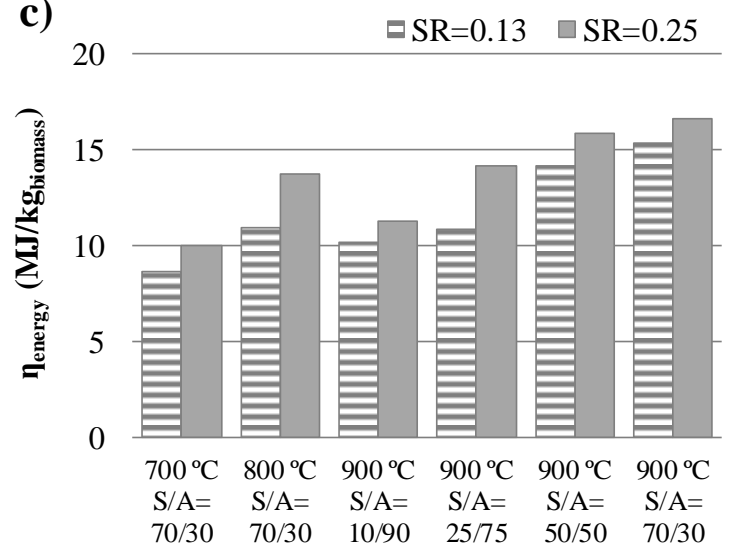

b)
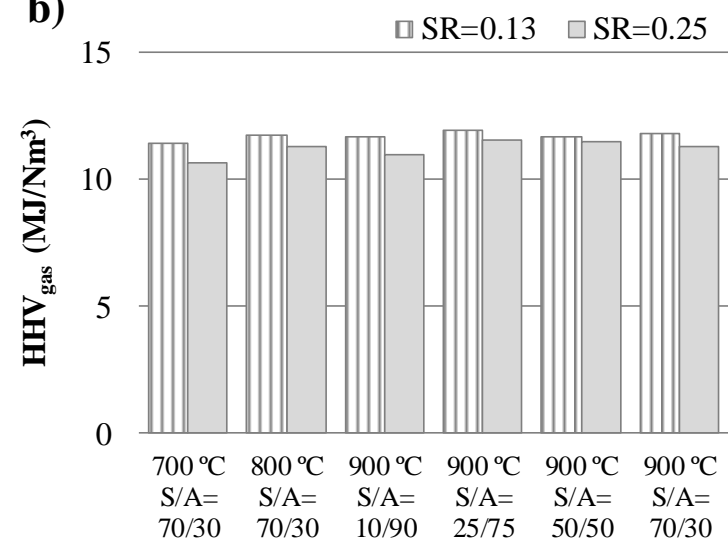

d)
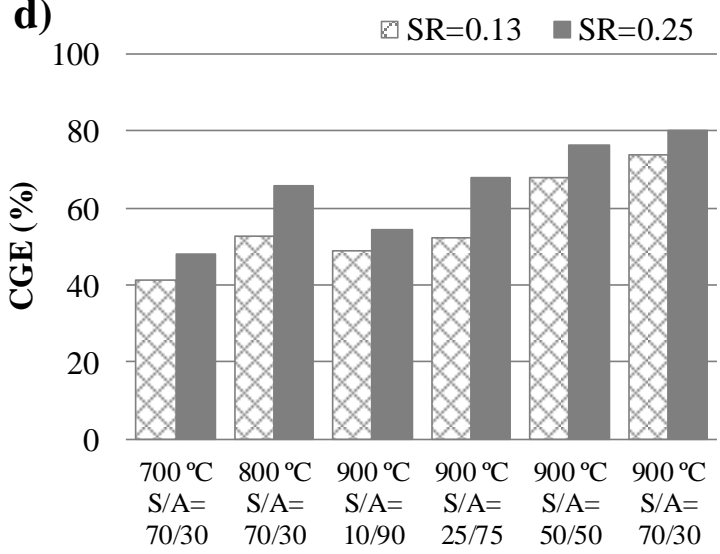

Fig. 5. Gas yield (a), higher heating value of the product gas (b), energy yield (c) and cold gas efficiency (d) from the gasification of PKS as a function of temperature, steam to air ratio (S/A) in the gasifying agent and SR. 
Fig. $5 \mathrm{~b}$ also shows that the calorific value of the product gas, $\mathrm{HHV}_{\mathrm{gas}}$, is only significantly increased when the temperature is raised from 700 to $800{ }^{\circ} \mathrm{C}$. However, for all the other conditions of temperature and S/A ratio, the results are very similar. On the contrary, as mentioned above, the $\mathrm{H}_{2}$ concentration and yield are clearly favored by temperature and S/A ratio. This means that these variables play a very important role in the gasification process when the hydrogen production wants to be maximized, although they seem less relevant if only the production of a fuel gas with higher calorific value is the objective of the process.

Therefore, it can be concluded that the production of $\mathrm{H}_{2}$ and combustible gas by biomass gasification in the bubbling fluidized bed studied, as well as the thermal efficiency of the process, are favored by higher temperatures and steam concentrations in the gasifying atmosphere. If all the results from the PKS gasification are taken into account, it may be deduced that the gasification conditions with the best performance results are $900{ }^{\circ} \mathrm{C}$, $\mathrm{S} / \mathrm{A}=70 / 30$ and $\mathrm{SR}=0.25$. Under these conditions, the product gas obtained contains 33.5 vol\% of $\mathrm{H}_{2}, 67.3 \mathrm{vol} \%$ of $\left[\mathrm{H}_{2}+\mathrm{CO}\right]$ and $76.4 \mathrm{vol} \%$ of $\left[\mathrm{H}_{2}+\mathrm{CO}+\mathrm{CH}_{4}\right]$. Moreover, the energy yield of the process reaches $16.6 \mathrm{MJ} / \mathrm{kg}_{\text {biomass, }}$ which means a CGE of $80 \%$.

\subsection{Gasification of different types of lignocellulosic biomass}

According to the results about the effect of the operating variables on the gasification performance shown above, the conditions selected for studying the gasification process of different types of biomass were $900^{\circ} \mathrm{C}$ and $\mathrm{S} / \mathrm{A}=70 / 30$, using SR values of 0.13 and 0.25. Fig. 6 shows the $\mathrm{N}_{2}$-free composition of the product gas for the experiments with all the biomasses studied using SR values of 0.13 and 0.25 . In relation to SR, the gas concentrations for all the biomasses follow the same trend than that explained above for PKS. Thus, when using a higher stoichiometric ratio in the experiments, $S R=0.25$, the concentrations of $\mathrm{H}_{2}, \mathrm{CO}$ and $\mathrm{CH}_{4}$ in the outlet gas are slightly lower than those obtained with $\mathrm{SR}=0.13$, while slightly higher $\mathrm{CO}_{2}$ concentrations are produced, due to a higher extent of the combustion reaction since more oxygen is available in the gasifying atmosphere. Therefore, as the gasification behavior of the different biomasses studied in relation to the stoichiometric ratio is similar, only the results for $\mathrm{SR}=0.25$ will be presented in this section since this condition has been demonstrated to give a better overall performance. 


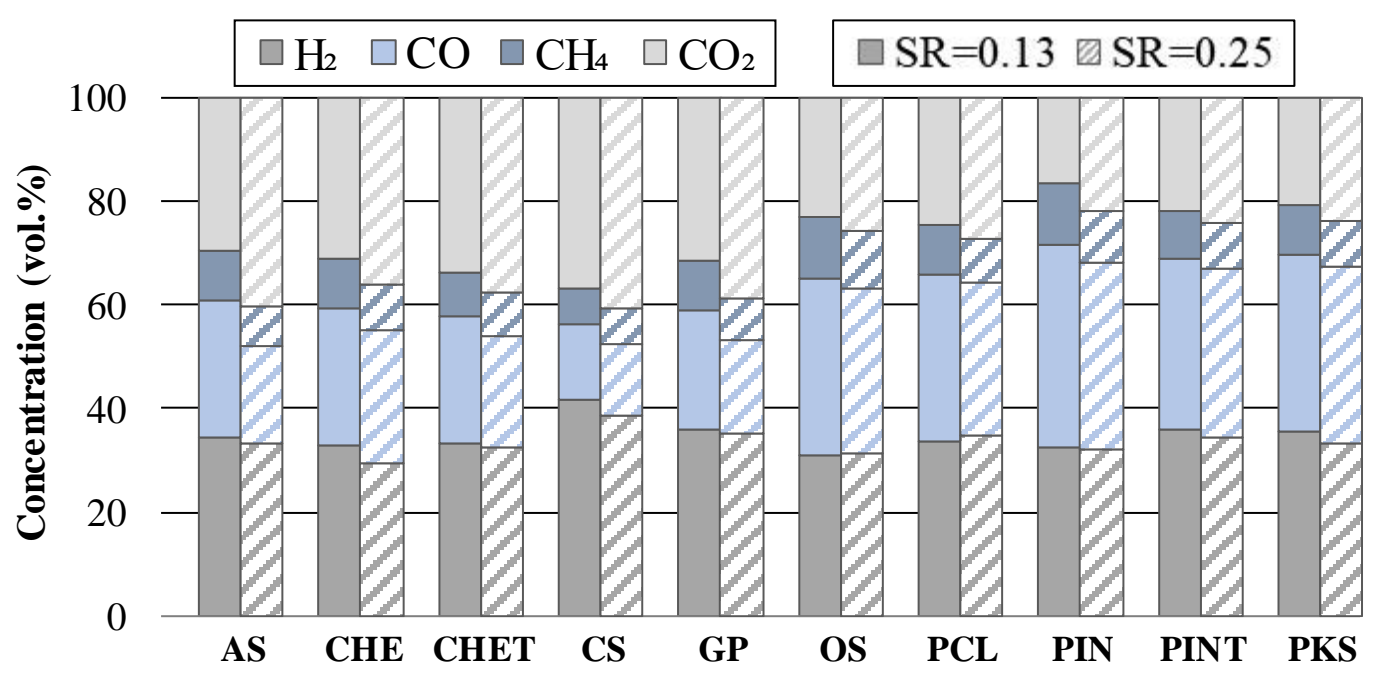

Fig. 6. $\mathrm{N}_{2}$-free composition of the product gas from the gasification at $900{ }^{\circ} \mathrm{C}$ and $\mathrm{S} / \mathrm{A}=70 / 30$ of all the biomasses studied using $\mathrm{SR}$ values of 0.13 and 0.25 .

The $\mathrm{N}_{2}$-free composition of the product gas for the experiments at $\mathrm{SR}=0.25$ with the biomasses studied is shown in Fig. 7. The biomasses in the $x$-axis are ordered from the lowest to the highest value of the variable represented in the $y$-axis. The $\mathrm{H}_{2}$ concentration in the product gas (Fig. 7a) for all the biomasses varied in a relatively narrow range of values, from 29.6 to 38.5 vol\%. These results are in agreement with those reported in literature for air-steam gasification in a fluidized bed at $900{ }^{\circ} \mathrm{C}$ of pine sawdust (39 vol\%) [23], for steam-oxygen gasification in a bubbling fluidized bed at $830^{\circ} \mathrm{C}$ of almond shells (30-33 vol\%) [24] and for air-steam gasification in a bubbling fluidized bed at $800{ }^{\circ} \mathrm{C}$ of wood pellets (25-31 vol\%) [44]. However, the CO content (Fig. 7b) showed higher differences, in the range of 14.1-35.8 vol\%. The $\mathrm{CH}_{4}$ concentration (Fig. 7c) showed the lowest values between the combustible gases produced, with a variation very small between the biomasses studied (6.7-11.2 vol\%). The $\mathrm{CO}_{2}$ content (Fig. 7d) is represented by ordering the biomasses in the $x$-axis from the highest to the lowest value of this parameter, which varied in the range of 22.0-40.7 vol\%. Thus, it can be seen that the order of the biomass samples is the same for the $\mathrm{CO}$ and $\mathrm{CO}_{2}$ contents, indicating that their values follow a clear opposite tendency. In this way, the biomasses analyzed could be distributed in three general groups according to the values of the gasification parameters analyzed: (i) CS, AS, GP, CHET and CHE; (ii) PCL; and (iii) OS, PINT, PKS and PIN. Thus, in general the biomasses in group (i) show the lowest values for the evaluated parameter, those in group (ii) have medium values, while biomasses in group (iii) present 
the highest values for the studied parameter. These three groups have been marked in Figs. 7-9 by squares. The order of the biomass samples according to the $\mathrm{CH}_{4}$ concentration is mostly similar, but the OS sample showed a slightly higher value of methane than other samples. However, as it can be seen in Fig. 7a, the order of the biomass samples according to their $\mathrm{H}_{2}$ content is different to the general pattern. The syngas (Fig. 7e) and the overall combustible gas (Fig. 7f) follow the same tendency to that observed for the $\mathrm{CO}$ concentration. This may be important if the gas obtained from biomass gasification is going to be directly used as fuel in internal combustion engines, gas turbines, furnaces, boilers or stoves.

a) 50

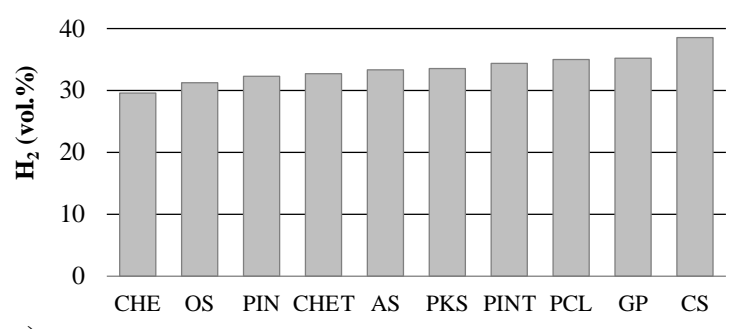

c) 50

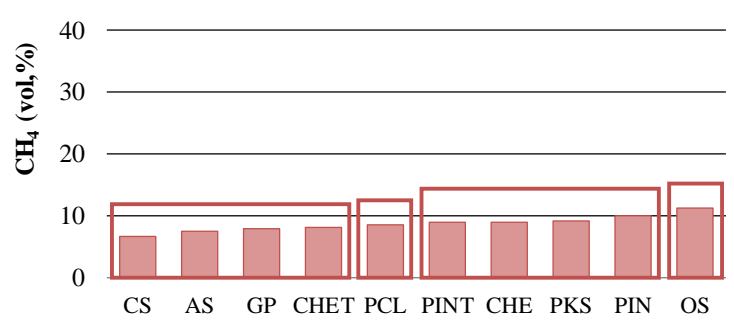

e) 100

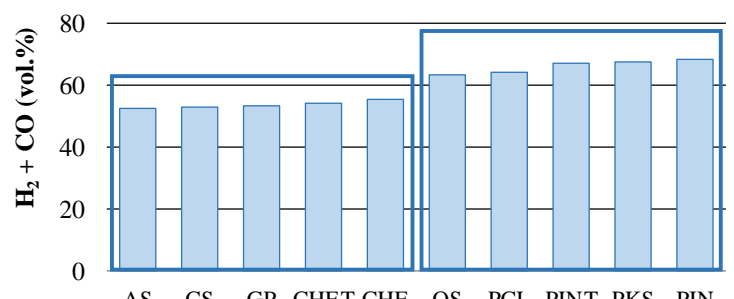

b) 50

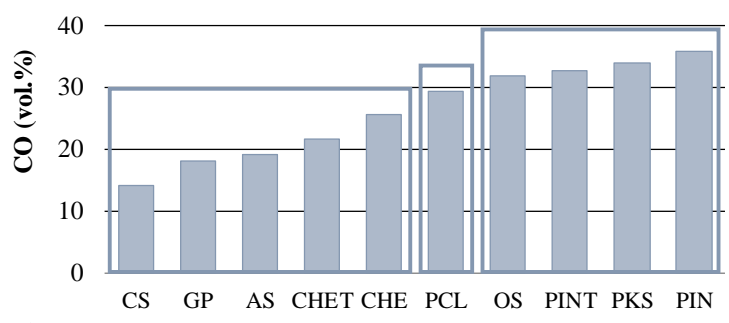

d) 50

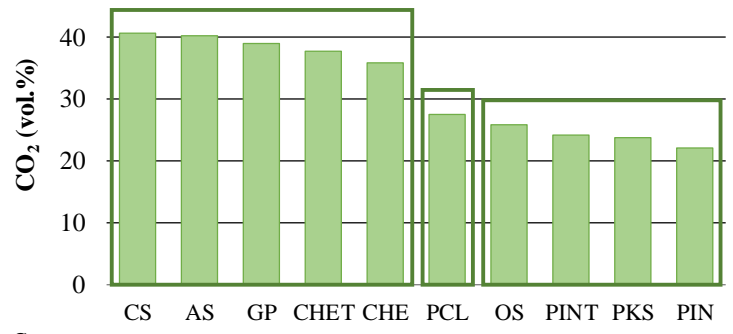

f) 100

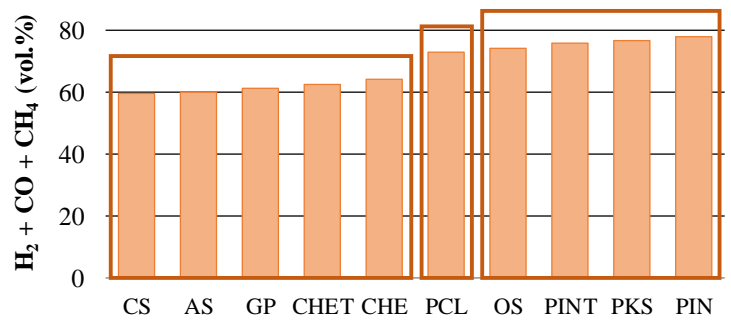

Fig. 7. $\mathrm{N}_{2}$-free composition of the product gas from the gasification at $900{ }^{\circ} \mathrm{C}, \mathrm{S} / \mathrm{A}=70 / 30$ and $\mathrm{SR}=0.25$ of all the biomasses studied: (a) $\mathrm{H}_{2}$; (b) $\mathrm{CO}$; (c) $\mathrm{CH}_{4}$; (d) $\mathrm{CO}_{2}$; (e) syngas; and (f) overall combustible gas.

The production of the main gases expressed in mol of gas component produced per mol of dry biomass for all the biomasses studied is shown in Fig. 8. Except for $\mathrm{CO}_{2}$, the general tendency in the order of the biomasses is similar to that found for the 
concentrations of gases. Thus, the biomasses with the lowest conversion are GP, CHE, AS, CS and CHET, followed by PCL, and then by PIN, OS, PKS and PINT. Moreover, Fig. $8 \mathrm{~g}$ shows the $\mathrm{H}_{2} / \mathrm{CO}$ molar ratio in the product gas for the gasification at $\mathrm{SR}=0.25$ of all the biomasses studied. The $\mathrm{H}_{2} / \mathrm{CO}$ ratio varied in a wide range of values, from 0.90 to 2.73. A high $\mathrm{H}_{2} / \mathrm{CO}$ ratio implies an enhanced steam reforming and WGS reactions during the gasification process. The $\mathrm{H}_{2} / \mathrm{CO}$ ratio in the syngas from biomass gasification has been reported to be usually less than $1 \mathrm{~mol} / \mathrm{mol}$ [45]. This ratio may be increased by the water gas shift reaction, so a downstream facility to adjust the $\mathrm{H}_{2} / \mathrm{CO}$ ratio is generally necessary prior to the chemical synthesis to obtain hydrogen to carbon monoxide ratios desired for particular syntheses. $\mathrm{H}_{2} / \mathrm{CO}$ mole ratios of 2 in the feed gas are required for producing optimum liquid hydrocarbon product yields by the Fischer-Tropsch process [46], values about 2 are also required for the synthesis of methanol, while $\mathrm{H}_{2} / \mathrm{CO}$ ratios about 3 are needed for the synthesis of methane [47]. In the present study, the concentration of $\mathrm{H}_{2}$ is higher than that of $\mathrm{CO}$ for many of the biomasses studied (CS, GP, AS, CHET, PCL, CHE and PINT), while PKS, OS and PIN showed a value of the $\mathrm{H}_{2} / \mathrm{CO}$ ratio close to unity. In general, the order of the biomasses shows a similar tendency to that already described.

The efficiency parameters for the gasification process are shown in Fig. 9. In general, the order of the biomasses follows the same explained tendency. The gas yield, $\eta_{\text {gas }}$, (Fig. 9a), defined as the volume of gas produced per kilogram of biomass, agrees with the results for the molar production of gases shown in Fig. 8. It varied between 0.8 and 1.6 $\mathrm{Nm}^{3} / \mathrm{kg}_{\text {biomass. }}$ Values around $1.1 \mathrm{Nm}^{3} / \mathrm{kg}_{\text {biomass }}$ have been reported in literature for airsteam gasification at $800{ }^{\circ} \mathrm{C}$ of wood pellets [44] and for steam-oxygen gasification at $830{ }^{\circ} \mathrm{C}$ of almond shells [24], while a higher value of $2.2 \mathrm{Nm}^{3} / \mathrm{kg}_{\text {biomass }}$ was obtained for air-steam gasification at $800{ }^{\circ} \mathrm{C}$ of pine sawdust [23].

The heating value of the product gas, $\mathrm{HHV}_{\text {gas }}$, (Fig. 9b) varied in a narrower range than the other variables $\left(8.7-11.7 \mathrm{MJ} / \mathrm{Nm}^{3}\right)$, and its values are in accordance with the concentrations of gases shown in Figs. 7e and 7f. OS shows a gas heating value higher than expected by the general tendency due to a higher content of methane in the product

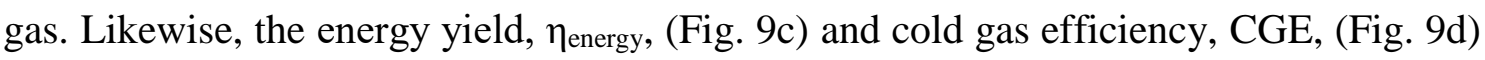
follow a similar tendency. Energy yield varied from 7.7 to $17.8 \mathrm{MJ} / \mathrm{kg}_{\text {biomass, }}$ while CGE varied between 41.0 and $82.4 \%$. CGE values within this range have been reported in 
literature for gasification of wood pellets (62\% [44], 72-78\% [48] or 82-88\%[49]). In the present work, the biomasses were not in pellet form, but efficiency values higher than $60 \%$ were also obtained for samples PCL, PIN, PKS, OS and PINT.

a) 3.0
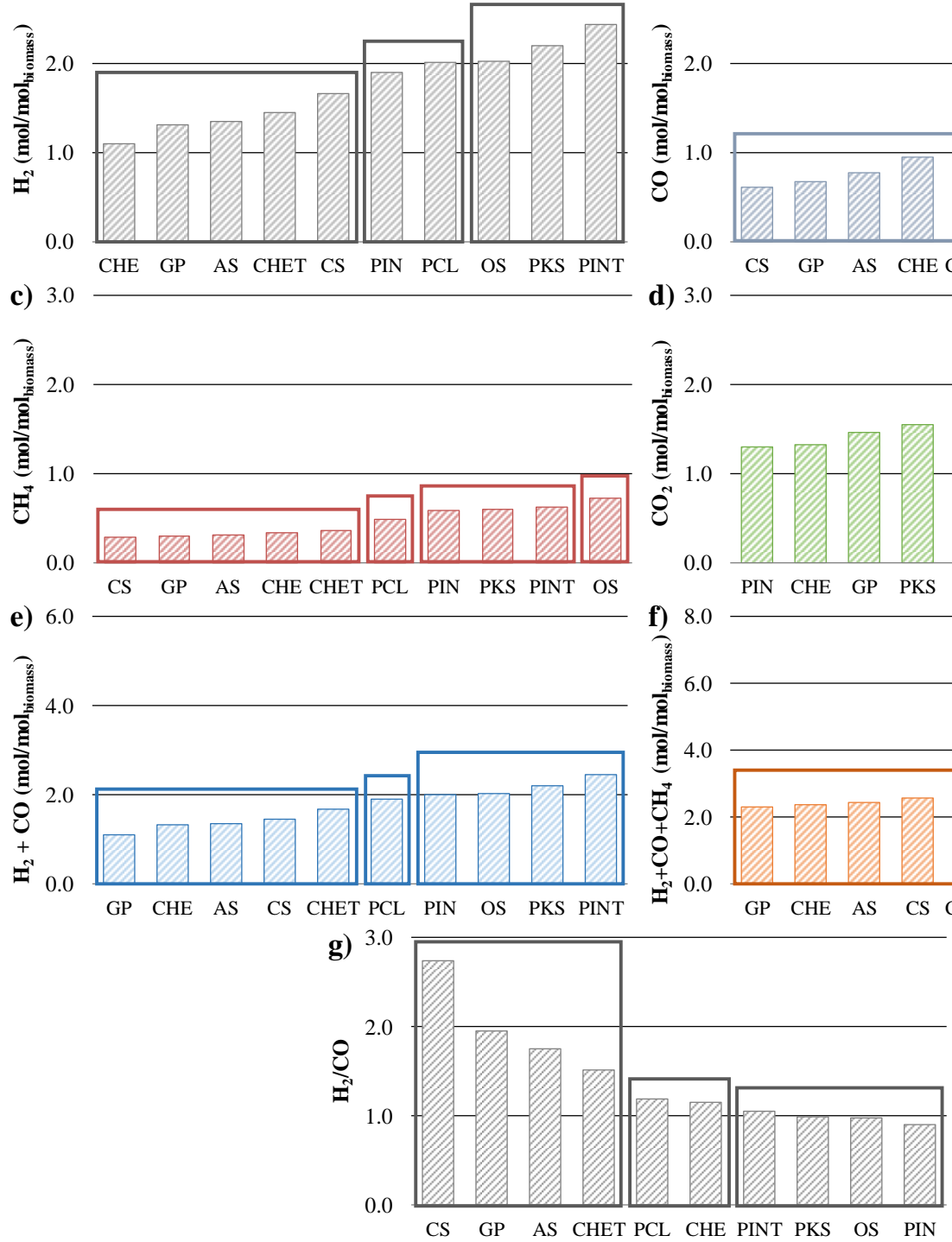

b) 3.0

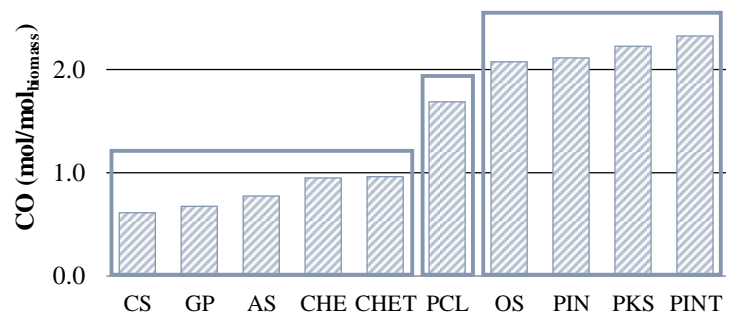

d) 3.0
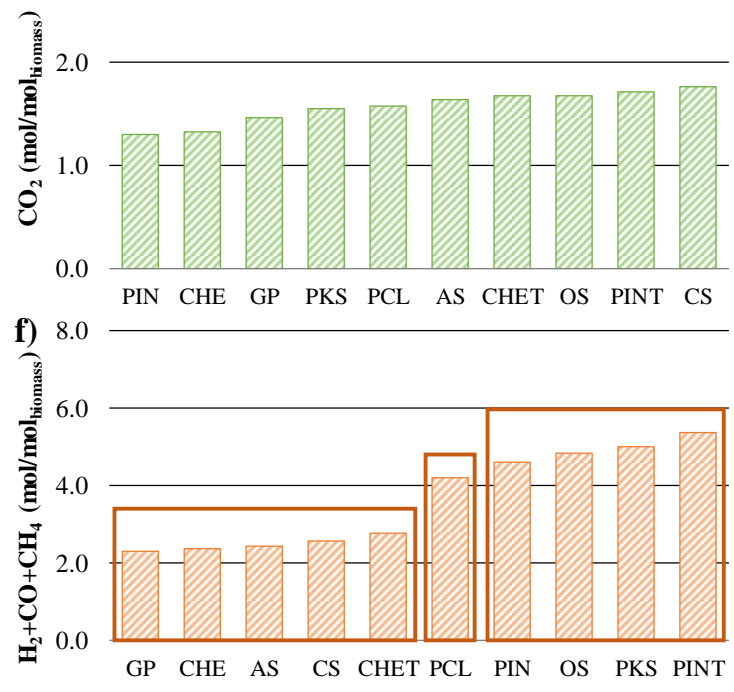

Fig. 8. Molar production of $\mathrm{H}_{2}$ (a), $\mathrm{CO}$ (b), $\mathrm{CH}_{4}$ (c), $\mathrm{CO}_{2}$ (d), syngas (e) and overall combustible gas (f), as well as molar $\mathrm{H}_{2} / \mathrm{CO}$ ratio in the product gas $(\mathrm{g})$, from the gasification at $900{ }^{\circ} \mathrm{C}, \mathrm{S} / \mathrm{A}=70 / 30$ and $\mathrm{SR}=0.25$ of all the biomasses studied. 
a) 2.0

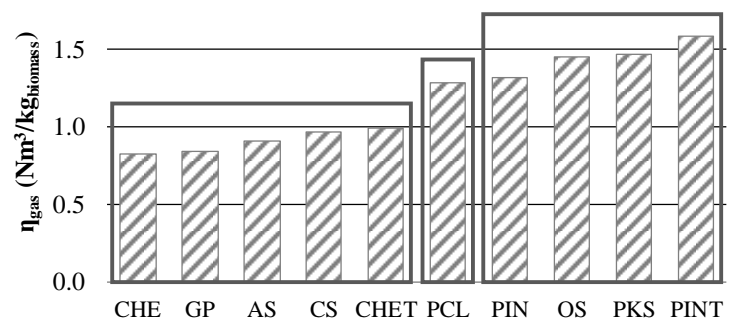

b) 15

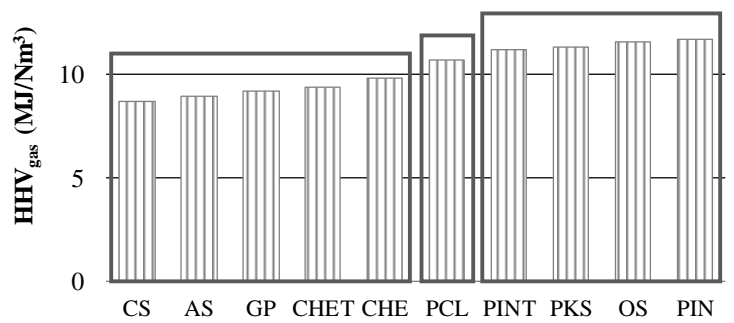

c) 25
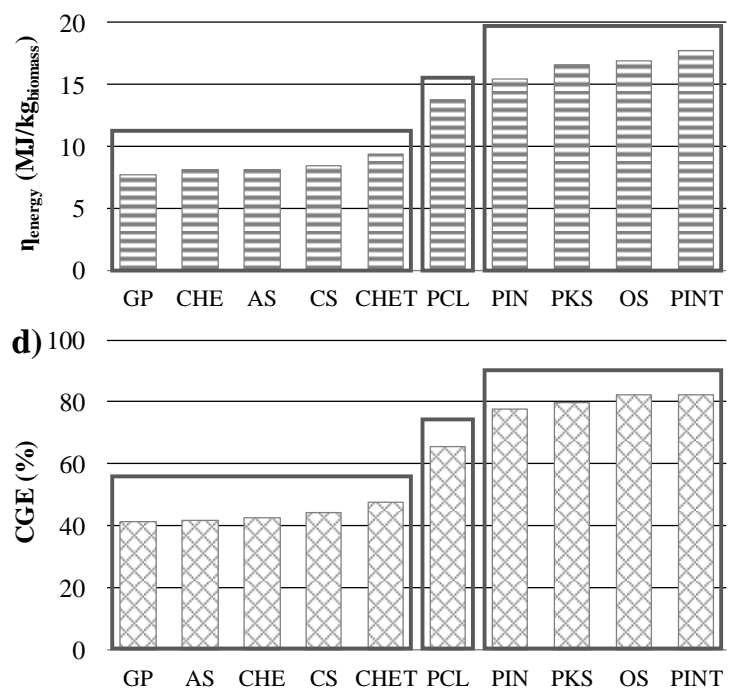

Fig. 9. Gas yield (a), higher heating value of the product gas (b), energy yield (c) and cold gas efficiency (d) from the gasification at $900{ }^{\circ} \mathrm{C}, \mathrm{S} / \mathrm{A}=70 / 30$ and $\mathrm{SR}=0.25$ of all the biomasses studied.

In relation to the gasification of torrefied biomass, the results for PIN and PINT, as well as those for CHE and CHET, show that, in general, the differences in the syngas and combustible gas productions (Figs. 7e and 7f, respectively) between the raw and torrefied biomass samples are very small. However, it may be detected that the $\mathrm{H}_{2}$ concentration (Fig. 7a) and the $\mathrm{H}_{2} / \mathrm{CO}$ ratio (Fig. 8g) are higher for torrefied samples than for raw biomasses. On the contrary, the $\mathrm{CO}$ (Fig. 7b) and $\mathrm{CH}_{4}$ (Fig. 7c) concentrations are slightly lower for torrefied than for raw samples. Similar tendencies from air gasification 
experiments of raw and torrefied pine have been reported in literature [34]. Therefore, if the main objective of the gasification process is to produce hydrogen, the use of torrefied biomass as feedstock could be interesting, although further research on this topic is still necessary. Kulkarni et al. [34] found a slightly higher volumetric concentration of combustible gas with raw biomass than with torrefied samples. This was also true in the present work, but the differences between torrefied (62.2 vol\% for CHET and 75.9 vol\% for PINT) and raw (64.1 vol\% for CHE and 78.0 vol\% for PIN) biomasses are small. Moreover, the gas heating value was reported to be slightly higher for raw biomasses [34]. A slightly higher $\mathrm{HHV}_{\text {gas }}$ for raw samples is also shown in Fig. 9b. Nevertheless, the gas yield is higher for torrefied biomasses (Fig. 9a), which results in slightly higher energy yield (Fig. 9c) and efficiency (Fig. 9d) values for the torrefied samples. In general, it can be concluded that the gasification performance in relation to the heating value of the combustible gas is quite similar for the torrefied samples and the corresponding raw biomasses after air-steam gasification under the conditions of this study. However, slightly higher efficiency results seem to be obtained using torrefied biomass. This means that it is possible to take advantage of all the benefits of the torrefaction process on the biomass properties (such as higher density that enhances its handling and transport [50], better grindability [51] or hydrophobicity [34] that improves its storage) without producing a loss in the gasification performance.

\subsection{Correlations between gasification performance and biomass properties}

Although it is very difficult to directly relate the gasification performance with the biomass characteristics due to the complexity of these materials and the complicated interactions between their properties, an attempt to find some correlations that help to explain the gasification results has been done in the present work. Thus, the different properties of the biomass samples studied have been compared with the gasification results obtained in the experimental tests. The most relevant relationships detected are explained below.

Fig. 10 shows a negative effect of the volatile matter content of the biomass on the $\mathrm{H}_{2}$ concentration in the product gas (Fig. 10a), but a positive effect on the CO concentration (Fig. 10b). If the volatile matter content in the biomass sample is higher, a higher production of $\mathrm{CO}$ could occur during the first stage of pyrolysis. This means a positive 
effect of the VM content on the syngas and combustible gas contents (Figs. 10c and 10d), and then on $\mathrm{HHV}_{\text {gas }}$ (Fig. 10e), but a negative effect on the $\mathrm{H}_{2} / \mathrm{CO}$ ratio (Fig. 10f). Fig. 11 shows the relationships between the elemental composition of the biomass and different gasification parameters. Likewise, a positive effect of the $\mathrm{C}$ content in the biomass on the CO (Fig. 11a), syngas (Fig. 11b) and combustible gas (Fig. 11c) concentrations, and hence on $\mathrm{HHV}_{\text {gas }}$ (Fig. 11d), $\eta_{\text {gas }}$ (Fig. 11e) and $\eta_{\text {energy }}$ (Fig. 11f), has been detected. In addition, Fig. 12 shows a positive effect of the $\mathrm{HHV}_{\text {biomass }}$ on the $\mathrm{CO}$ (Fig. 12a), syngas (Fig. 12b) and combustible gas (Fig. 12c) concentrations, and also on $\mathrm{HHV}_{\text {gas }}$ (Fig. 12d). It meant a significant positive effect of the $\mathrm{HHV}_{\text {biomass }}$ on $\eta_{\text {gas }}$ (Fig. 12e) and $\eta_{\text {energy }}$ (Fig. 12f). However, it should be pointed out that these biomass properties (VM, C content and $\mathrm{HHV}_{\text {biomass }}$ ) showed a negative or no relevant effect on the $\mathrm{H}_{2}$ production. The only positive correlation detected for the $\mathrm{H}_{2}$ concentration was found with the biomass H/O ratio (Table 1), as it is shown in Fig. 11g. Prasad and Kuester [52] reported a positive correlation between the $\mathrm{H} / \mathrm{O}$ ratio of the biomass and the $\mathrm{H}_{2} / \mathrm{CO}$ ratio in the product gas from biomass pyrolysis, which was not found in the present work.

In a previous work on the kinetic analysis of many of the biomass fuels used in the present study [53], the steam gasification reactivity of the samples was measured by means of a reactivity index at $900{ }^{\circ} \mathrm{C}$, which was calculated as follows [54]:

$R=\frac{0.5}{t_{0.5}}$

where $t_{0.5}$ represents the time required to reach $50 \%$ of carbon conversion. This index provides information about the gasification reaction rate at a given temperature. Fig. 13 shows the effect of this reactivity index for the biomasses studied on the gasification performance. A positive effect of the reactivity index at $900{ }^{\circ} \mathrm{C}$ on the $\mathrm{H}_{2}$ concentration in the product gas (Fig. 13a) was found, but negative on the CO concentration (Fig. 13b). It implies a clear positive effect on the $\mathrm{H}_{2} / \mathrm{CO}$ ratio (Fig. 13c). This corroborates that a higher reactivity under steam of the biomass samples favors the $\mathrm{H}_{2}$ production by the reforming reaction. 

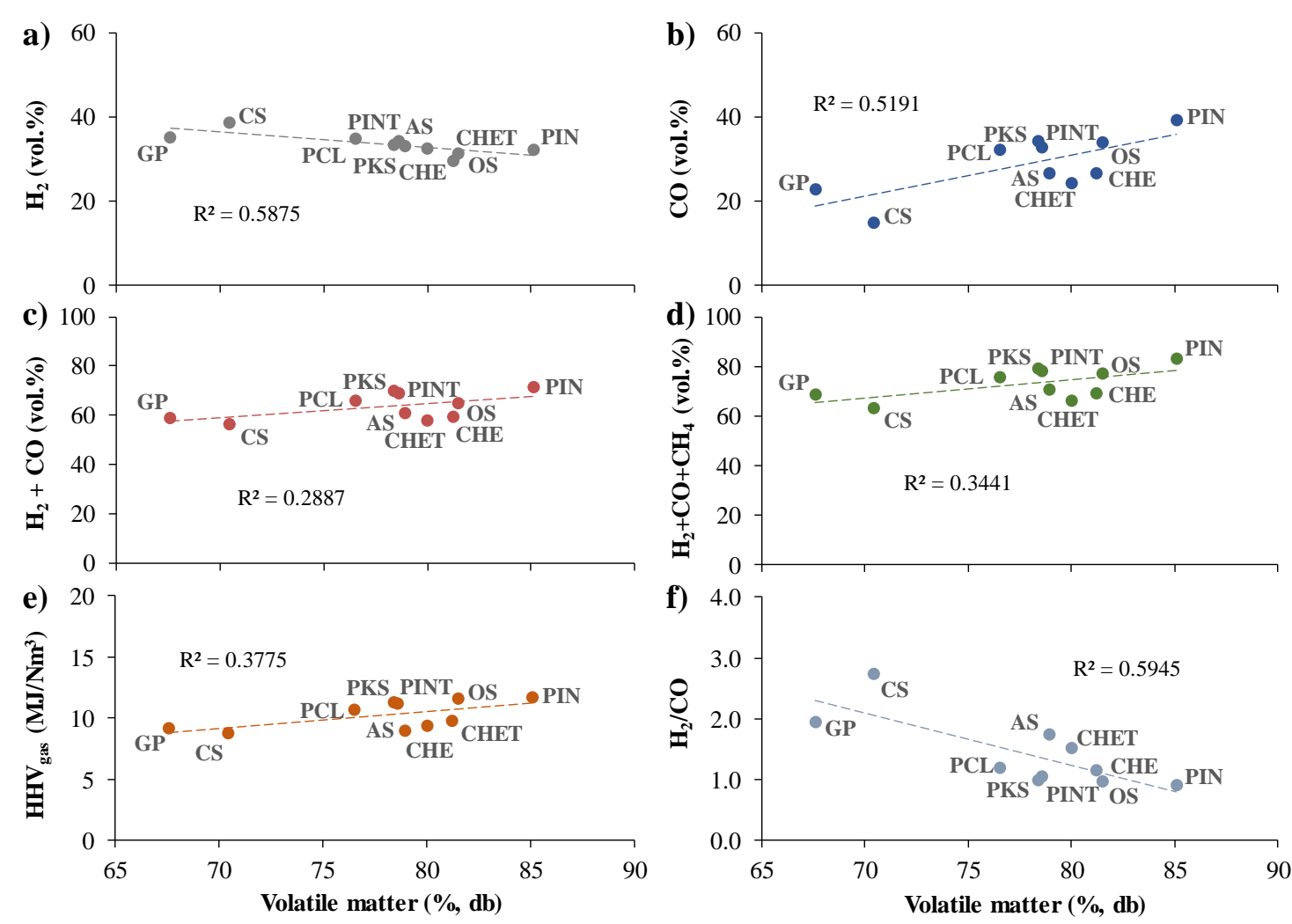

Fig. 10. Relationship between volatile matter content of the biomass and $\mathrm{H}_{2}$ concentration (a), CO concentration (b), syngas concentration (c), overall combustible gas concentration (d), higher heating value of the product gas (e) and $\mathrm{H}_{2} / \mathrm{CO}$ molar ratio (f).

On the other hand, the helium density of the biomass samples was also calculated (Table 1) since its value gives a relatively accurate determination of the true density (also called particle density), which is defined as the mass per unit volume occupied by the solid constituent of the sample [38]. This parameter showed a negative effect on the $\mathrm{H}_{2}$ concentration (Fig. 13d). Sample density influences the char structure, which is strongly related to the char reactivity [55]. Therefore, the results indicate that a lower biomass density could lead to a higher reactivity of the char to the steam gasification/reforming reactions which generate hydrogen. This is in accordance with the positive relationship found between the $\mathrm{H}_{2}$ concentration and the reactivity index at $900{ }^{\circ} \mathrm{C}$. On the other hand, it has been reported that the temperature gradient within a sample under pyrolysis conditions increases as particle density increases. It results in a slower particle heating rate and leads to an increase in the time taken for biomass conversion [56]. Likewise, the intra-particle volatiles residence time increases with the particle density, making more time available for tar to participate in intra-particle secondary reactions. In addition, lower 
temperatures during primary pyrolysis favor charring reactions, which lead to decrease the tar yield while increasing the gas, and possibly char, production [57]. Although the particle size of the biomass used in the present work is small, some effect of the biomass density during the pyrolysis step could have occurred. A lower volatiles residence time within the particles for samples with a lower density may have contributed to a faster release of volatiles, favoring the steam water gas and reforming reactions and hence more production of $\mathrm{H}_{2}$.
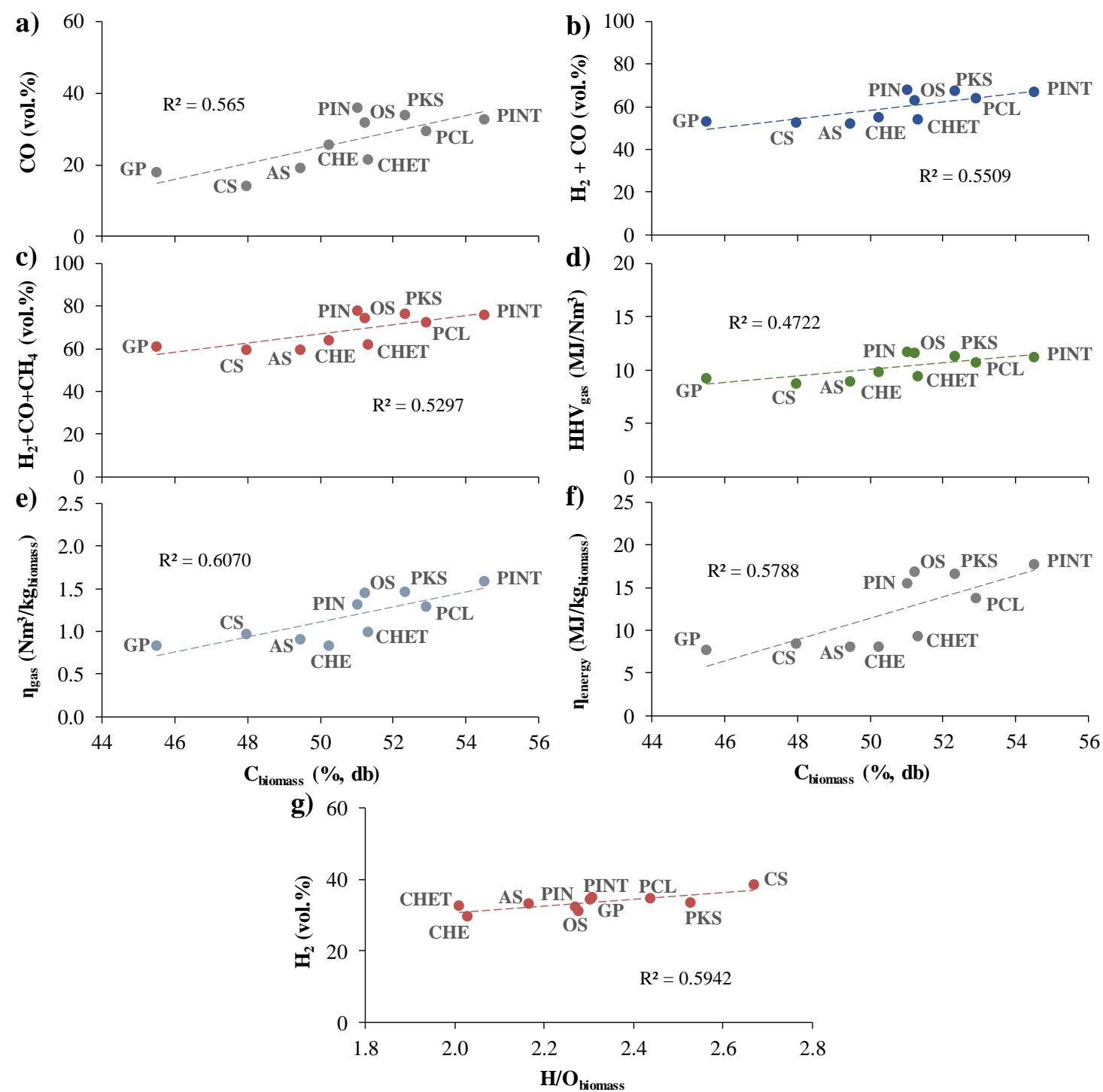

Fig. 11. Relationship between $\mathrm{C}$ content of the biomass and CO concentration (a), syngas concentration (b), overall combustible gas concentration (c), higher heating value of the product gas (d), gas yield (e) and energy yield (f), as well as relationship between H/O ratio in biomass and $\mathrm{H}_{2}$ concentration $(\mathrm{g})$. 
Summarizing, the $\mathrm{H}_{2}$ concentration in the product gas showed a positive tendency with the $\mathrm{H} / \mathrm{O}$ ratio and reactivity index at $900{ }^{\circ} \mathrm{C}$, but negative with the helium density and $\mathrm{VM}$ content. The $\mathrm{H}_{2} / \mathrm{CO}$ ratio was also positively related with the reactivity index at $900{ }^{\circ} \mathrm{C}$, but negatively with the VM content of the biomass. On the contrary, higher VM content, $\mathrm{C}$ content and $\mathrm{HHV}$ value of the biomass seemed to favor the $\mathrm{CO}$, syngas and combustible gas concentrations, as well as the $\mathrm{HHV}_{\text {gas }}$ and the gas and energy yields.
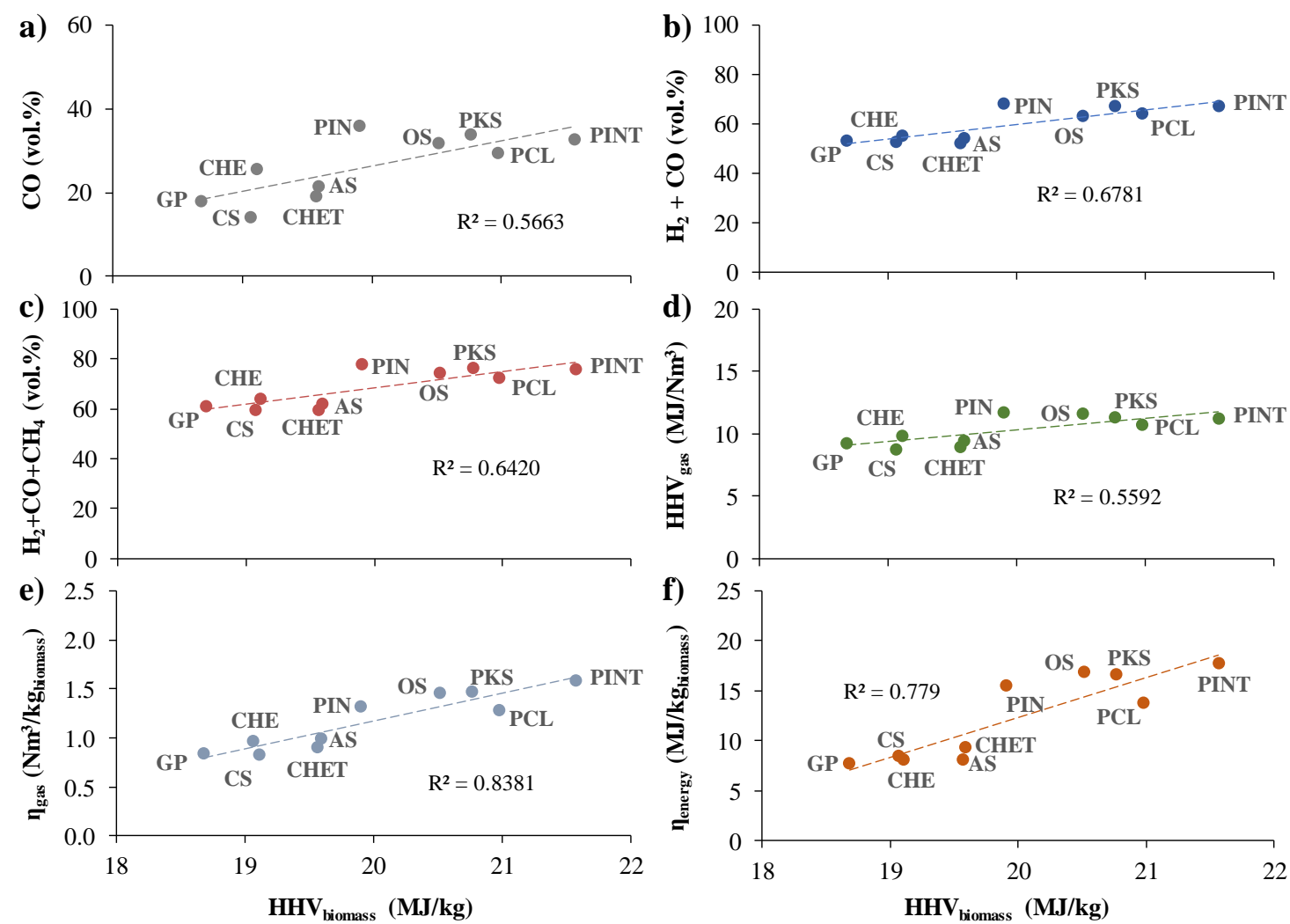

Fig. 12. Relationship between higher heating value of the biomass and $\mathrm{CO}$ concentration (a), syngas concentration (b), overall combustible gas concentration (c), higher heating value of the product gas (d), gas yield (e) and energy yield (f). 

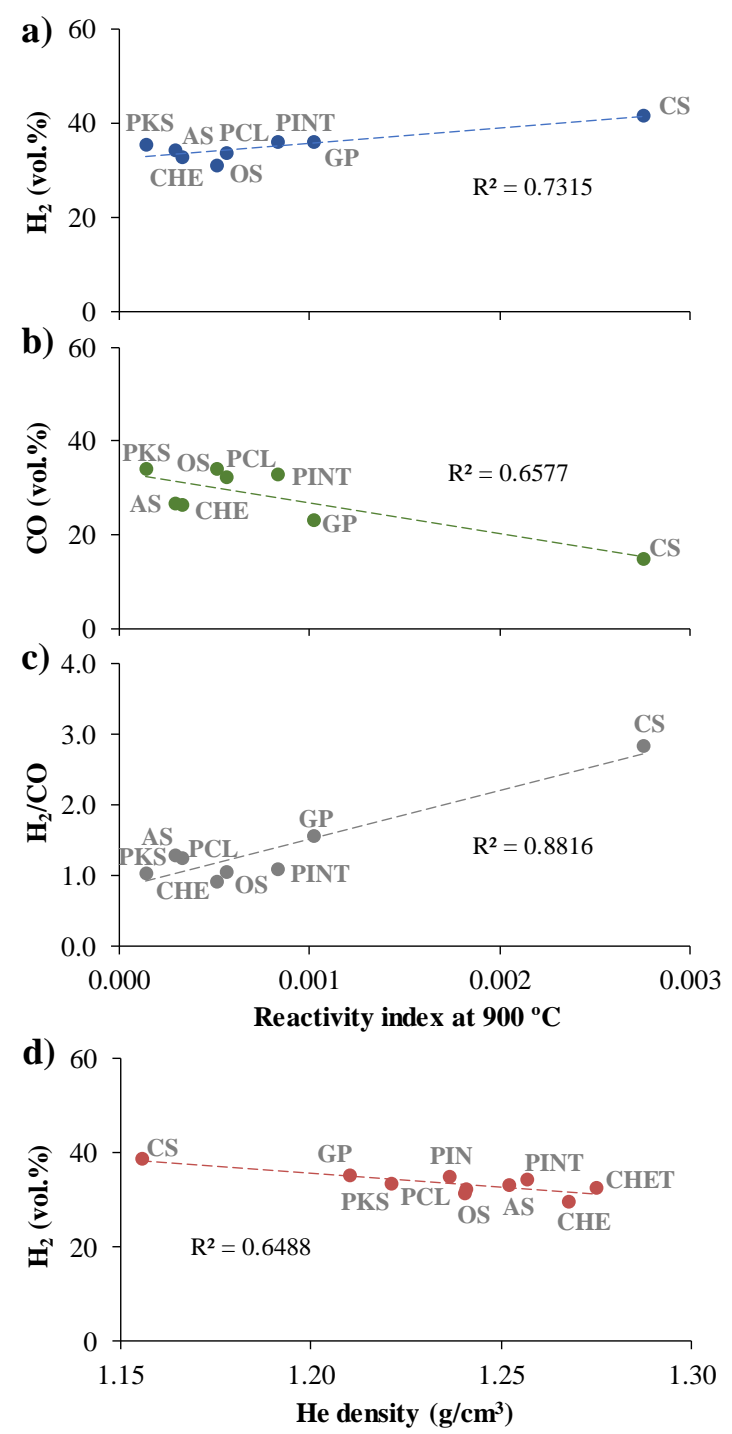

Fig. 13. Relationship between reactivity index at $900{ }^{\circ} \mathrm{C}$ of the biomass and $\mathrm{H}_{2}$ concentration (a), $\mathrm{CO}$ concentration (b) and $\mathrm{H}_{2} / \mathrm{CO}$ molar ratio (c), as well as relationship between $\mathrm{He}$ density of the biomass and $\mathrm{H}_{2}$ concentration (d).

As explained above, except for the $\mathrm{H}_{2}$ concentration, a general tendency in the order of the biomasses with respect to the gas composition results and efficiency parameters was detected. Thus, the lowest results were for CS, AS, GP, CHET and CHE, followed by PCL, and then by OS, PINT, PKS and PIN. Biomass samples GP and CS presented the lowest values of $\mathrm{VM}$ content, $\mathrm{C}$ content and $\mathrm{HHV}_{\text {biomass }}$ between all the biomasses studied. The CHET, CHE and AS samples also have low values of $\mathrm{HHV}_{\text {biomass }}$ and medium values of VM and C contents. Samples PCL, OS, PKS, PIN and PINT have higher $\mathrm{HHV}_{\text {biomass }}$ values and medium or high values of $\mathrm{VM}$ and $\mathrm{C}$ contents. As it was 
expected, in general none of the indicated relations showed a coefficient of correlation very high, which indicates that one given biomass property cannot explain a gasification parameter on its own. Nevertheless, the correlation results are still relevant and may help to understand the gasification behavior of the biomass samples under the conditions analyzed.

\section{Conclusions}

The feasibility of the air-steam gasification of a number of different types of lignocellulosic biomass has been verified experimentally in a bubbling fluidized bed plant. The gasification performance was evaluated by the gas composition, gas yield, gas heating value and thermal efficiency. The effect of the main process variables on the gasification performance was studied and the best experimental conditions between those studied were identified as $900{ }^{\circ} \mathrm{C}, \mathrm{S} / \mathrm{A}=70 / 30$ and $\mathrm{SR}=0.25$. Higher temperature and steam concentration in the gasifying agent favor the biomass conversion into valuable combustible gases.

The results of this study have shown that unconventional types of biomass, such as wastes from food industries (almond shells, cocoa shells, grape pomace, olive stones, pine kernel shells), wastes from forests (pine cone leaf) and hardwood biomass (chestnut) may be successfully gasified. The fluidization of all the biomasses studied was feasible using coal ash as bed material in the fluidized bed reactor used. In comparison with the gasification performance obtained for the most traditionally used biomass, pine sawdust, the rest of biomasses studied showed comparable results in the case of PKS, OS and PCL, and slightly lower values, but still acceptable, in the case of AS, CHE, GP and CS. This suggests that those biomasses with lower results could be gasified in mixtures with others which present better performance. Torrefaction of biomass could be used with the aim of improving the biomass properties related to handling and storage, without worsening the gasification performance. Torrefied samples showed similar combustible gas production but slightly better efficiency results than the corresponding raw biomasses. The synthesis gas obtained from biomass gasification showed a relatively high calorific value, the conversion of the biomass samples into valuable products was significant, and very high $\mathrm{H}_{2} / \mathrm{CO}$ ratio values may be produced. 
Some relevant correlations between the gasification performance parameters and the biomass properties were detected. Thus, the results suggest positive effects of the volatile matter content, $\mathrm{C}$ content and $\mathrm{HHV}$ of the biomass on the $\mathrm{CO}$ and combustible gas concentrations, on the calorific value of the product gas, as well as on the gas and energy yields. The $\mathrm{H}_{2}$ concentration in the product gas was favored by the $\mathrm{H} / \mathrm{O}$ ratio and steam reactivity of the biomass.

\section{Acknowledgements}

This work has received financial support from the Spanish MINECO (ENE2014-53515P), cofinanced by the European Regional Development Fund (ERDF). M.P. GonzálezVázquez acknowledges a fellowship awarded by the Spanish MINECO (FPI program), cofinanced by the European Social Fund.

\section{References}

[1] IEA. Global Energy \& $\mathrm{CO}_{2}$ Status Report 2017. International Energy Agency (IEA); 2017.

[2] Zhao L, Lu Y. Hydrogen production by biomass gasification in a supercritical water fluidized bed reactor: A CFD-DEM study. The Journal of Supercritical Fluids 2018;131:26-36.

[3] Raheem A, Ji G, Memon A, Sivasangar S, Wang W, Zhao M, et al. Catalytic gasification of algal biomass for hydrogen-rich gas production: Parametric optimization via central composite design. Energy Convers Manage 2018;158:235-45.

[4] Yao J, Kraussler M, Benedikt F, Hofbauer H. Techno-economic assessment of hydrogen production based on dual fluidized bed biomass steam gasification, biogas steam reforming, and alkaline water electrolysis processes. Energy Convers Manage 2017;145:278-92.

[5] Kraussler M, Binder M, Schindler P, Hofbauer H. Hydrogen production within a polygeneration concept based on dual fluidized bed biomass steam gasification. Biomass Bioenerg 2018;111:320-9.

[6] Koppatz S, Schmid JC, Pfeifer C, Hofbauer H. The Effect of Bed Particle Inventories with Different Particle Sizes in a Dual Fluidized Bed Pilot Plant for Biomass Steam Gasification. Ind Eng Chem Res 2012;51:10492-502.

[7] Sisinni M, Di Carlo A, Bocci E, Micangeli A, Naso V. Hydrogen-Rich Gas Production by Sorption Enhanced Steam Reforming of Woodgas Containing TAR over a Commercial Ni Catalyst and Calcined Dolomite as $\mathrm{CO}_{2}$ Sorbent. Energies 2013;6:3167.

[8] Yang H, Wang D, Li B, Zeng Z, Qu L, Zhang W, et al. Effects of potassium salts loading on calcium oxide on the hydrogen production from pyrolysis-gasification of biomass. Bioresour Technol 2018;249:744-50.

[9] Arregi A, Amutio M, Lopez G, Bilbao J, Olazar M. Evaluation of thermochemical routes for hydrogen production from biomass: A review. Energy Convers Manage 2018;165:696-719.

[10] Xiao Y, Xu S, Song Y, Shan Y, Wang C, Wang G. Biomass steam gasification for hydrogen-rich gas production in a decoupled dual loop gasification system. Fuel Process Technol 2017;165:54-61.

[11] Aydin ES, Yucel O, Sadikoglu H. Numerical and experimental investigation of hydrogen-rich syngas production via biomass gasification. Int J Hydrogen Energy 2018;43:1105-15.

[12] Molino A, Chianese S, Musmarra D. Biomass gasification technology: The state of the art overview. Journal of Energy Chemistry 2016;25:10-25.

[13] Karatas H, Akgun F. Experimental results of gasification of walnut shell and pistachio shell in a bubbling fluidized bed gasifier under air and steam atmospheres. Fuel 2018;214:285-92.

[14] Ku X, Jin H, Lin J. Comparison of gasification performances between raw and torrefied biomasses in an air-blown fluidized-bed gasifier. Chem Eng Sci 2017;168:235-49. 
[15] Anukam A, Mamphweli S, Reddy P, Meyer E, Okoh O. Pre-processing of sugarcane bagasse for gasification in a downdraft biomass gasifier system: A comprehensive review. Renew Sust Energ Rev 2016;66:775-801.

[16] Fremaux S, Beheshti S-M, Ghassemi H, Shahsavan-Markadeh R. An experimental study on hydrogenrich gas production via steam gasification of biomass in a research-scale fluidized bed. Energy Convers Manage 2015;91:427-32.

[17] Gil J, Aznar MP, Caballero MA, Francés E, Corella J. Biomass Gasification in Fluidized Bed at Pilot Scale with Steam-Oxygen Mixtures. Product Distribution for Very Different Operating Conditions. Energy Fuels 1997;11:1109-18.

[18] Wan Ab Karim Ghani WA, Moghadam RA, Salleh MAM, Alias AB. Air Gasification of Agricultural Waste in a Fluidized Bed Gasifier: Hydrogen Production Performance. Energies 2009;2:258.

[19] Xiong Q, Yeganeh MM, Yaghoubi E, Asadi A, Doranehgard MH, Hong K. Parametric investigation on biomass gasification in a fluidized bed gasifier and conceptual design of gasifier. Chemical Engineering and Processing - Process Intensification 2018;127:271-91.

[20] Yaghoubi E, Xiong Q, Doranehgard MH, Yeganeh MM, Shahriari G, Bidabadi M. The effect of different operational parameters on hydrogen rich syngas production from biomass gasification in a dual fluidized bed gasifier. Chemical Engineering and Processing - Process Intensification 2018;126:210-21.

[21] Nam H, Rodriguez-Alejandro DA, Adhikari S, Brodbeck C, Taylor S, Johnson J. Experimental investigation of hardwood air gasification in a pilot scale bubbling fluidized bed reactor and CFD simulation of jet/grid and pressure conditions. Energy Convers Manage 2018;168:599-610.

[22] Campoy M, Gómez-Barea A, Villanueva AL, Ollero P. Air-Steam Gasification of Biomass in a Fluidized Bed under Simulated Autothermal and Adiabatic Conditions. Ind Eng Chem Res 2008;47:595765 .

[23] Lv P, Chang J, Xiong Z, Huang H, Wu C, Chen Y, et al. Biomass Air-Steam Gasification in a Fluidized Bed to Produce Hydrogen-Rich Gas. Energy Fuels 2003;17:677-82.

[24] Barisano D, Canneto G, Nanna F, Alvino E, Pinto G, Villone A, et al. Steam/oxygen biomass gasification at pilot scale in an internally circulating bubbling fluidized bed reactor. Fuel Process Technol 2016;141:74-81.

[25] de Sales CAVB, Maya DMY, Lora EES, Jaén RL, Reyes AMM, González AM, et al. Experimental study on biomass (eucalyptus spp.) gasification in a two-stage downdraft reactor by using mixtures of air, saturated steam and oxygen as gasifying agents. Energy Convers Manage 2017;145:314-23.

[26] Prestipino M, Chiodo V, Maisano S, Zafarana G, Urbani F, Galvagno A. Hydrogen rich syngas production by air-steam gasification of citrus peel residues from citrus juice manufacturing: Experimental and simulation activities. Int J Hydrogen Energy 2017;42:26816-27.

[27] Corella J, Herguido J, Gonzalez-Saiz J, Alday FJ, Rodriguez-Trujillo JL. Fluidized Bed Steam Gasification of Biomass with Dolomite and with a Commercial FCC Catalyst. In: Bridgwater AV, Kuester JL, editors. Research in Thermochemical Biomass Conversion. Dordrecht: Springer Netherlands; 1988. p. 754-65.

[28] Detchusananard T, Im-orb K, Ponpesh P, Arpornwichanop A. Biomass gasification integrated with $\mathrm{CO}_{2}$ capture processes for high-purity hydrogen production: Process performance and energy analysis. Energy Convers Manage 2018;171:1560-72.

[29] Tian Y, Zhou X, Lin S, Ji X, Bai J, Xu M. Syngas production from air-steam gasification of biomass with natural catalysts. Sci Total Environ 2018;645:518-23.

[30] Couto ND, Silva VB, Rouboa A. Assessment on steam gasification of municipal solid waste against biomass substrates. Energy Convers Manage 2016;124:92-103.

[31] Herguido J, Corella J, Gonzalez-Saiz J. Steam gasification of lignocellulosic residues in a fluidized bed at a small pilot scale. Effect of the type of feedstock. Ind Eng Chem Res 1992;31:1274-82.

[32] van der Drift A, van Doorn J, Vermeulen JW. Ten residual biomass fuels for circulating fluidized-bed gasification. Biomass Bioenerg 2001;20:45-56.

[33] Chew JJ, Doshi V. Recent advances in biomass pretreatment - Torrefaction fundamentals and technology. Renew Sust Energ Rev 2011;15:4212-22.

[34] Kulkarni A, Baker R, Abdoulmomine N, Adhikari S, Bhavnani S. Experimental study of torrefied pine as a gasification fuel using a bubbling fluidized bed gasifier. Renew Energy 2016;93:460-8.

[35] Popp J, Lakner Z, Harangi-Rákos M, Fári M. The effect of bioenergy expansion: Food, energy, and environment. Renew Sust Energ Rev 2014;32:559-78.

[36] Telmo C, Lousada J, Moreira N. Proximate analysis, backwards stepwise regression between gross calorific value, ultimate and chemical analysis of wood. Bioresour Technol 2010;101:3808-15. 
[37] Obernberger I, Brunner T, Bärnthaler G. Chemical properties of solid biofuels-significance and impact. Biomass Bioenerg 2006;30:973-82.

[38] De S, Agarwal AK, Moholkar VS, Thallada B. Coal and Biomass Gasification: Recent Advances and Future Challenges: Springer Singapore; 2017.

[39] Narváez I, Orío A, Aznar MP, Corella J. Biomass Gasification with Air in an Atmospheric Bubbling Fluidized Bed. Effect of Six Operational Variables on the Quality of the Produced Raw Gas. Ind Eng Chem Res 1996;35:2110-20.

[40] Gil J, Corella J, Aznar MaP, Caballero MA. Biomass gasification in atmospheric and bubbling fluidized bed: Effect of the type of gasifying agent on the product distribution. Biomass Bioenerg 1999;17:389-403.

[41] Hernández JJ, Aranda G, Barba J, Mendoza JM. Effect of steam content in the air-steam flow on biomass entrained flow gasification. Fuel Process Technol 2012;99:43-55.

[42] AENOR. UNE-EN ISO 6976: Gas natural. Cálculo del poder calorífico, densidad, densidad relativa e índice de Wobbe a partir de la composición. Asociación Española de Normalización y Certificación, AENOR; 2005.

[43] Weiland F, Nordwaeger M, Olofsson I, Wiinikka H, Nordin A. Entrained flow gasification of torrefied wood residues. Fuel Process Technol 2014;125:51-8.

[44] Campoy M, Gómez-Barea A, Vidal FB, Ollero P. Air-steam gasification of biomass in a fluidised bed: Process optimisation by enriched air. Fuel Process Technol 2009;90:677-85.

[45] Zeng J, Xiao R, Zeng D, Zhao Y, Zhang H, Shen D. High $\mathrm{H}_{2} / \mathrm{CO}$ Ratio Syngas Production from Chemical Looping Gasification of Sawdust in a Dual Fluidized Bed Gasifier. Energy Fuels 2016;30:176470.

[46] Pala LPR, Wang Q, Kolb G, Hessel V. Steam gasification of biomass with subsequent syngas adjustment using shift reaction for syngas production: An Aspen Plus model. Renew Energy 2017;101:48492.

[47] Wender I. Reactions of synthesis gas. Fuel Process Technol 1996;48:189-297.

[48] Dudyński M, van Dyk JC, Kwiatkowski K, Sosnowska M. Biomass gasification: Influence of torrefaction on syngas production and tar formation. Fuel Process Technol 2015;131:203-12.

[49] Mandl C, Obernberger I, Scharler IR. Characterisation of fuel bound nitrogen in the gasification process and the staged combustion of producer gas from the updraft gasification of softwood pellets. Biomass Bioenerg 2011;35:4595-604.

[50] Pinto F, Gominho J, André RN, Gonçalves D, Miranda M, Varela F, et al. Improvement of gasification performance of Eucalyptus globulus stumps with torrefaction and densification pre-treatments. Fuel 2017;206:289-99.

[51] Gil MV, García R, Pevida C, Rubiera F. Grindability and combustion behavior of coal and torrefied biomass blends. Bioresour Technol 2015;191:205-12.

[52] Prasad BVRK, Kuester JL. Process analysis of a dual fluidized bed biomass gasification system. Ind Eng Chem Res 1988;27:304-10.

[53] González-Vázquez MP, García R, Gil MV, Pevida C, Rubiera F. Unconventional biomass fuels for steam gasification: Kinetic analysis and effect of ash composition on reactivity. Energy 2018;155:426-37. [54] Fermoso J, Gil MV, Borrego AG, Pevida C, Pis JJ, Rubiera F. Effect of the Pressure and Temperature of Devolatilization on the Morphology and Steam Gasification Reactivity of Coal Chars. Energy Fuels 2010;24:5586-95.

[55] Morin M, Pécate S, Hémati M, Kara Y. Pyrolysis of biomass in a batch fluidized bed reactor: Effect of the pyrolysis conditions and the nature of the biomass on the physicochemical properties and the reactivity of char. J Anal Appl Pyrolysis 2016;122:511-23.

[56] Di Blasi C. Influences of physical properties on biomass devolatilization characteristics. Fuel 1997;76:957-64.

[57] Okekunle PO, Adeoye OO. Numerical investigation of the effects of some selected thermo-physical properties on products evolution and yields during biomass pyrolysis. Biofuels 2018;9:415-28. 